\title{
Cochrane
}

Library

Cochrane Database of Systematic Reviews

\section{Insecticide space spraying for preventing malaria transmission} (Review)

Pryce J, Choi L, Richardson M, Malone D

Pryce J, Choi L, Richardson M, Malone D.

Insecticide space spraying for preventing malaria transmission.

Cochrane Database of Systematic Reviews 2018, Issue 11. Art. No.: CD012689.

DOI: 10.1002/14651858.CD012689.pub2.

www.cochranelibrary.com

Insecticide space spraying for preventing malaria transmission (Review) 
TABLE OF CONTENTS

HEADER 1

ABSTRACT

PLAIN LANGUAGE SUMMARY

SUMMARY OF FINDINGS

BACKGROUND

Figure 1.

OBJECTIVES

METHODS

RESULTS

Figure 2.

Figure 3.

Figure 4.

Figure 5.

Figure 6.

Figure 7.

Figure 8.

Figure 9.

Figure 10.

DISCUSSION

AUTHORS' CONCLUSIONS

ACKNOWLEDGEMENTS

REFERENCES

CHARACTERISTICS OF STUDIES

DATA AND ANALYSES

Analysis 1.1. Comparison 1 Space spraying versus no space spraying, Outcome 1 Incidence of malaria (step rate ratio: indicating the impact of space spraying at the first pre-intervention time point).

Analysis 1.2. Comparison 1 Space spraying versus no space spraying, Outcome 2 Incidence of malaria (slope rate ratio: indicating the proportion of cases reduced per post-intervention time point).

ADDITIONAL TABLES

APPENDICES

CONTRIBUTIONS OF AUTHORS

DECLARATIONS OF INTEREST

SOURCES OF SUPPORT

DIFFERENCES BETWEEN PROTOCOL AND REVIEW

INDEX TERMS 
[Intervention Review]

\section{Insecticide space spraying for preventing malaria transmission}

Joseph Pryce ${ }^{1}$, Leslie Choi ${ }^{1}$, Marty Richardson ${ }^{2}$, David Malone ${ }^{3}$

1Department of Clinical Sciences, Liverpool School of Tropical Medicine, Liverpool, UK. ${ }^{2}$ Cochrane Infectious Diseases Group, Liverpool School of Tropical Medicine, Liverpool, UK. 3IVCC, Liverpool School of Tropical Medicine, Liverpool, UK

Contact address: Joseph Pryce, Department of Clinical Sciences, Liverpool School of Tropical Medicine, Pembroke Place, Liverpool, L3 5QA, UK. joseph.pryce@lstmed.ac.uk.

Editorial group: Cochrane Infectious Diseases Group.

Publication status and date: Unchanged, published in Issue 11, 2018.

Citation: Pryce J, Choi L, Richardson M, Malone D. Insecticide space spraying for preventing malaria transmission. Cochrane Database of Systematic Reviews 2018, Issue 11. Art. No.: CD012689. DOI: 10.1002/14651858.CD012689.pub2.

Copyright @ 2018 The Authors. Cochrane Database of Systematic Reviews published by John Wiley \& Sons, Ltd. on behalf of The Cochrane Collaboration. This is an open access article under the terms of the Creative Commons Attribution-Non-Commercial Licence, which permits use, distribution and reproduction in any medium, provided the original work is properly cited and is not used for commercial purposes.

\section{A B S T R A C T}

\section{Background}

Space spraying is the dispersal of a liquid fog of insecticide into an outdoor area to kill adult insects. It has been regularly used in public health and pest control programmes, including use as an emergency response to malaria epidemics. This Cochrane Review aims to assist the decision-making of malaria vector control programmes by summarizing the evidence of the impact of space spraying on malaria transmission.

\section{Objectives}

The review's primary objective was to evaluate the impact of space spraying on malaria transmission, or the incremental impact when applied in combination with other malaria control methods, in comparison to equivalent conditions with no space spraying intervention.

To guide future evaluations of space spraying, a secondary objective was to identify and summarize the range of space spraying strategies that have been trialled, those which were promising and warrant further evaluation, and those which appear unlikely to warrant further evaluation (for example, if they were not feasible to implement, or were unacceptable to the population).

\section{Search methods}

We searched the Cochrane Infectious Diseases Group Specialized Register; the Cochrane Central Register of Controlled Trials (CENTRAL), published in the Cochrane Library; PubMed (MEDLINE); Embase (OVID), CAB Abstracts (Web of Science), LILACS (BIREME), the World Health Organization (WHO) International Clinical Trials Registry Platform, and ClinicalTrials.gov up to 18 April 2018. We contacted organizations for ongoing and unpublished trials, and checked the reference lists of all included studies for relevant studies.

\section{Selection criteria}

We included cluster-randomized controlled trials, interrupted time series (ITS) studies, randomized cross-over studies, and controlled before-and-after (CBA) studies comparing space spraying with no space spraying that met the inclusion criteria for the review.

\section{Data collection and analysis}

Two review authors independently assessed trials for eligibility and risk of bias, and extracted the data. For ITS studies, we present findings graphically, and estimated the effect of space spraying on the step change and the slope change. We assessed the certainty of evidence using the GRADE approach. 


\section{Main results}

Two ITS studies, conducted between 1972 and 1984, met our inclusion criteria for the primary objective, and one study contributed to the quantitative analysis. This study was conducted in India, reported the incidence of malaria in four separate sites, and covered a total population of 18,460 people. In the pooled analysis across sites, there was no step effect for the incidence of uncomplicated malaria (step rate ratio $1.00,95 \%$ confidence interval $(\mathrm{Cl}) 0.51$ to 1.92$)$. There was an effect on the slope: the number of cases was reduced by $15 \%$ per month (slope rate ratio $0.85,95 \% \mathrm{Cl} 0.79$ to 0.91 ). Using these ratios, we estimated the effect of 12 months of space spraying on malaria incidence to be a reduction from 6 cases to 1 case per month per 1000 population ( $95 \% \mathrm{Cl} 0$ to 2 cases, very low-certainty evidence). The second study reported the impact of space spraying on malaria incidence and adult mosquito density in a population of 15,106 in Haiti, but it did not provide data from previous years. Thus, we could not estimate an effect of space spraying that was independent from temporal trends.

For the review's secondary objective, we identified a further two studies in addition to the two ITS studies; both used a CBA design and were conducted between 1973 and 2000. The four studies used a range of delivery methods including handheld, vehicle-mounted, and aircraftmounted spraying equipment. A variety of insecticides, doses, and spraying times were also used, with methods typically determined based on environmental factors and vector profiles.

\section{Authors' conclusions}

Evidence from one state in India conducted over 30 years ago suggests an effect of space spraying on the incidence of malaria, but the certainty of the evidence is very low. Reliable research in a variety of settings will help establish whether and when this intervention may be worthwhile.

12 April 2019

Up to date

All studies incorporated from most recent search

All eligible published studies found in the last search (18 Apr, 2018) were included

\section{PLAIN LANGUAGE SUMMARY}

\section{Insecticide space spraying for preventing malaria transmission}

\section{What is space spraying and how might it work?}

Space spraying is the outdoor spraying of insecticides to kill adult insects. The insecticide is dispersed using hand-held, vehicle-mounted or aircraft-mounted equipment to produce a fog. Space spraying is regularly used in public health and pest control programmes, including use as an emergency response to malaria epidemics. Insecticide-treated bed nets and indoor spraying of insecticides are the two interventions most commonly used by malaria programmes to control mosquito populations. Both interventions are effective at reducing human contact with indoor-biting mosquito species. If successful, space spraying reduces populations of outdoor-biting mosquitoes, and may help reduce malaria transmission from the mosquito species least affected by typical control efforts. At present, however, there remains widespread uncertainty over whether space spraying has any impact on malaria transmission.

\section{What is the aim of the review?}

In order to guide decision-making for malaria control programmes, the aim of this Cochrane Review was to summarize the actions taken and reported findings of trials evaluating the impact of space spraying on malaria transmission.

\section{What are the main findings of the review?}

After searching for relevant trials up to 18 April 2018, we identified four studies conducted between 1972 and 2000. Across the four studies, a range of insecticide delivery methods were used, including handheld, vehicle-mounted, and aircraft-mounted spraying equipment. A variety of different insecticides, doses, and spraying times were also used to suit the local environment and the behaviour of the targeted mosquito species.

In three studies, the evidence was considered to be unsuitable for reliably assessing the impact of space spraying on the number of cases of malaria. The remaining study, which took place in a single state in India and covered a combined population of 18,460 people, reported the number of malaria cases in the years preceding and following the introduction of space spraying. The evidence suggested that space spraying led to a decrease in the number of cases of malaria, but as the trial was conducted over 30 years ago and within one state in India, we cannot be certain that these findings are applicable in other areas where malaria occurs. Reliable research in a variety of settings will help to establish whether and when this intervention may be worthwhile. 


\section{SUMMARY OF FINDINGS}

\section{Summary of findings for the main comparison. 'Summary of findings' table 1}

\section{Space spraying compared to no space spraying for reducing malaria transmission}

Patient or population: people of all ages

Setting: malaria transmission areas

Intervention: space spraying

Comparison: no space spraying

\begin{tabular}{|c|c|c|c|c|c|c|}
\hline \multirow[t]{2}{*}{ Outcomes } & \multicolumn{2}{|c|}{ Anticipated absolute effects* $(95 \% \mathrm{Cl})$} & \multirow{2}{*}{$\begin{array}{l}\text { Relative effect } \\
(95 \% \mathrm{Cl})\end{array}$} & \multirow{2}{*}{$\begin{array}{l}\text { Number of par- } \\
\text { ticipants } \\
\text { (studies) }\end{array}$} & \multirow{2}{*}{$\begin{array}{l}\text { Certainty of the evi- } \\
\text { dence } \\
\text { (GRADE) }\end{array}$} & \multirow[t]{2}{*}{ Comments } \\
\hline & $\begin{array}{l}\text { Risk with no } \\
\text { space sprayin- } \\
\text { ga }\end{array}$ & $\begin{array}{l}\text { Risk following space } \\
\text { sprayingb }\end{array}$ & & & & \\
\hline $\begin{array}{l}\text { Malaria cases } \\
\text { per month }\end{array}$ & 6 per 1000 & $\begin{array}{l}\text { Instant effect: } 6 \text { per } 1000 \\
\text { ( } 3 \text { to } 12 \text { ) } \\
\text { Effect after } 12 \text { months fol- } \\
\text { low-up: } 1 \text { per } 1000 \\
\text { (0 to } 2 \text { per } 1000 \text { ) }\end{array}$ & $\begin{array}{l}\text { Step rate ratio: } \\
1.00 \\
(0.51 \text { to } 1.92) \\
\text { Slope rate ratio: } \\
0.85 \\
(0.79 \text { to } 0.91)\end{array}$ & $\begin{array}{l}\text { (1 observation- } \\
\text { al study: } 4 \text { sites) }\end{array}$ & $\begin{array}{l}\oplus \ominus \ominus \ominus \\
\text { VERY LOWc,d,e } \\
\text { downgraded due to } \\
\text { risk of bias, indirect- } \\
\text { ness, and impreci- } \\
\text { sion }\end{array}$ & $\begin{array}{l}\text { We do not know if space spraying } \\
\text { causes an immediate shift in the trend } \\
\text { of malaria incidence over time or a } \\
\text { change in the slope of the trend (that } \\
\text { is, a proportional reduction in cases } \\
\text { per month). }\end{array}$ \\
\hline
\end{tabular}

*The risk in the intervention group (and its $95 \% \mathrm{Cl}$ ) is based on the assumed risk in the comparison group and the relative effect of the intervention (and its $95 \% \mathrm{Cl}$ ). Abbreviations: $\mathrm{Cl}$ : confidence interval.

\section{GRADE Working Group grades of evidence}

High certainty: we are very confident that the true effect lies close to that of the estimate of the effect

Moderate certainty: we are moderately confident in the effect estimate: The true effect is likely to be close to the estimate of the effect, but there is a possibility that it is substantially different

Low certainty: our confidence in the effect estimate is limited: The true effect may be substantially different from the estimate of the effect

Very low certainty: we have very little confidence in the effect estimate: The true effect is likely to be substantially different from the estimate of effect

aWe estimated the risk with no space spraying by calculating the mean monthly incidence of malaria across each of the study sites. We include only incidence data from complete years (January to December without intervention) in the calculation.

bWe estimated the instant effect following the introduction of space spraying by multiplying the risk with no space spraying by the step rate ratio (i.e. the 'immediate' shift in the incidence trend). We used the $\mathrm{Cl}$ for the step rate ratio to calculate the $\mathrm{Cl}$ for the instant effect. We estimated the effect after 12 months follow-up by multiplying the risk with no space spraying by the slope rate ratio (the reduction in cases of malaria per additional month of follow-up) for each of the 12 months. We used the Cl for the slope rate ratio to calculate the $\mathrm{Cl}$ for the risk following 12 months of the intervention.

cDowngraded by one for serious risk of bias: Tewari 1990 shows evidence of selective reporting of incidence, with data presented from just four of the 24 villages in Vanapuram indicated to have received the intervention. 
dDowngraded by one for serious indirectness: only one study is included in the analysis, conducted in Tamil Nadu, India. It is unclear if the effect reported here would be similar in other malaria transmission areas with different ecological landscapes, climates and primary vector species.

eDowngraded by one for serious imprecision: the $\mathrm{Cl}$ of the step rate ratio is large and includes both a sizeable increase and a reduction in malaria incidence. 


\section{B A C K G R O U N D}

\section{Description of the condition}

With one child dying from malaria every two minutes, malaria remains the world's most serious vector-borne disease. In 2016, an estimated 216 million new cases arose globally and the disease caused 445,000 deaths, of which more than two-thirds were children under the age of five (WHO 2017a). Most of the malaria burden falls on people living in sub-Saharan Africa, where $90 \%$ of the total incidence and 91\% of all deaths occur (WHO 2017a). Malaria is also a leading cause of global morbidity and was responsible for between 63 and 110 million disability-adjusted life years (DALYs) in 2010 (Murray 2012).

The Plasmodium species that cause malaria are transmitted by the bite of a female Anopheles mosquito, and malaria prevention methods are predominantly geared towards reducing human contact with infective mosquitoes. Insecticide-treated nets (ITNs) and indoor residual spraying (IRS) prevent malaria transmission in a variety of settings, and these methods have formed a central component of the global strategy for malaria control (Lengeler 2004; Pluess 2010; WHO 2015). Between 2010 and 2015 the estimated percentage of the at-risk population sleeping under an ITN rose from $30 \%$ to $53 \%$. This drive has coincided with a reduction in disease incidence of $21 \%$, while malaria-related deaths have fallen by $29 \%$ (WHO 2016a). However, these successes have not been universal. Of the 91 countries with active transmission of malaria, only 40 are on course to achieve the Global Technical Strategy's target of a 40\% incidence reduction by 2020 (WHO 2015; WHO 2016a).

\section{Description of the intervention}

Space spraying refers to the process of dispersing liquid droplets of insecticide into an area as a fog, with the aim of knocking down and killing adult insects (Figure 1). For the purposes of this Cochrane Review, the term implies distribution of insecticide at a population level, rather than household use. There are two different mechanisms for generating the fog for space spraying. Thermal fogs use hot gas to vaporize a solution of insecticide in a typically oil-based carrier liquid. Upon spraying, the vapour interacts with colder air and forms a dense fog. In contrast, cold fogs are formed without the use of external heat, passing the insecticide mixture instead through a mechanical apparatus such as a highpressure nozzle or high-speed air flow. Cold fogging commonly uses ultra-low-volume (ULV) preparations of insecticide. The insecticide may also be delivered in three different ways; using equipment that is either hand-held, vehicle-mounted, or applied from an aircraft (WHO 2003). Table 1 details the insecticides and doses currently recommended by the World Health Organization (WHO) for space spraying use to control mosquitoes (WHO 2016b).

\section{Figure 1. Space spraying with hand-held equipment to control the mosquito population in Thailand}

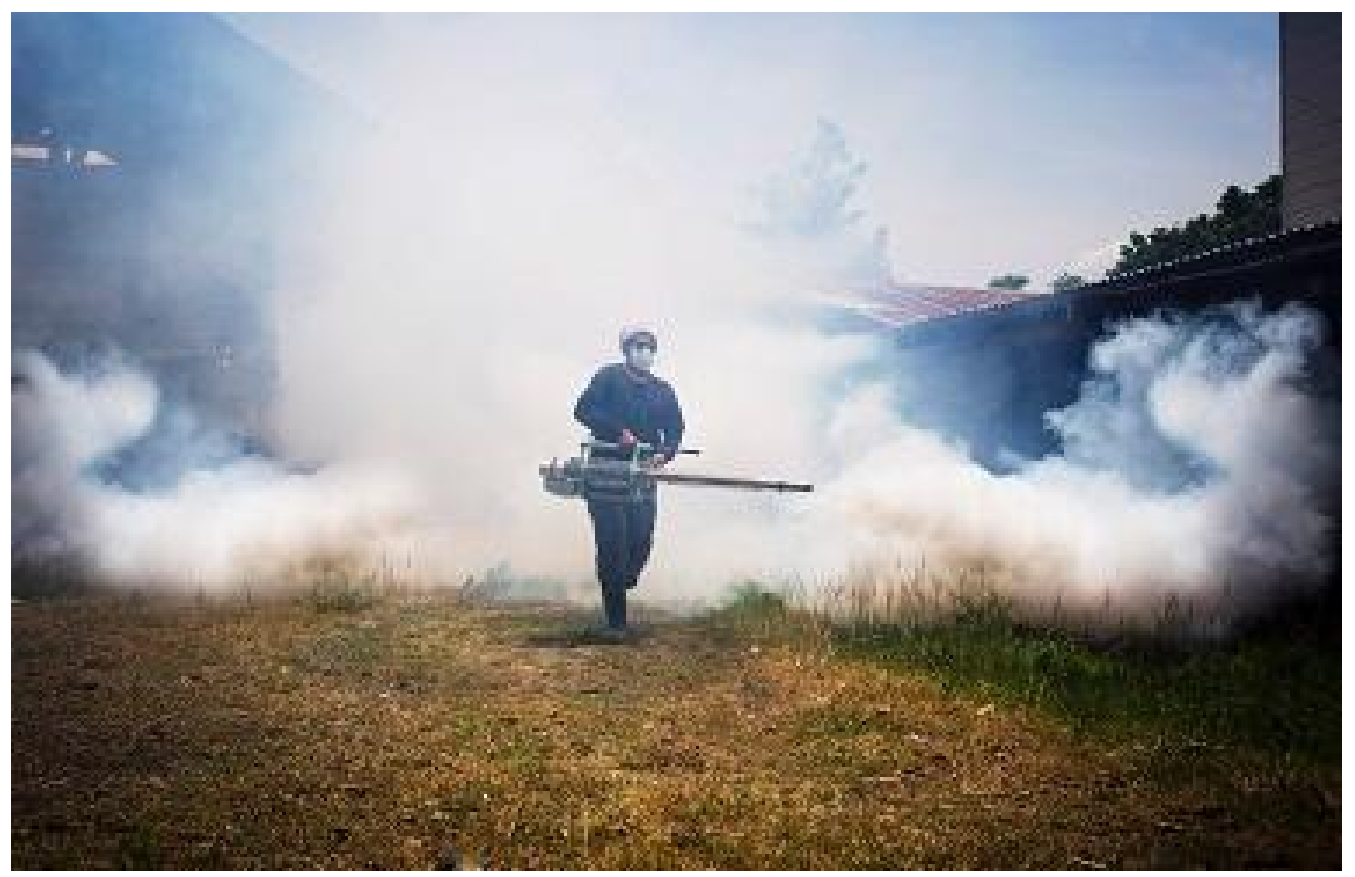

Space spraying is regularly used in other public health and pest control programmes. The intervention is an often-used strategy in response to outbreaks of dengue fever, a mosquito-borne viral disease with endemic regions that overlap extensively with those of malaria (Epelboin 2012). However, there is a lack of robust evidence that the strategy impacts on dengue transmission (Esu 2010). Both ground and aerial spraying of insecticides have also been regularly used for the control of tsetse flies and for other pests of public health or agricultural importance (WHO 2003; Adam 2013).
Both thermal and cold fog applications are only effective while the droplets remain airborne (WHO 2003). The length of this time is mainly dependent on the size of droplets distributed; a 10 $\mu \mathrm{m}$ droplet spray will fall by 10 metres in one hour, while 100 $\mu \mathrm{m}$ droplets will fall the same distance in 36 seconds. Anopheles mosquitoes typically bite in the evening, at night and in the early morning, and it is recommended that the timing of spraying coincides with this period of peak activity (WHO 2003; Pates 2005). Space spraying is sometimes conducted during the day. In these 
cases, the intention is to reach and kill mosquitoes in their resting locations, or induce them to take flight through the fog (Najera 2003). Space spraying targets only the current adult mosquito population. The technique has little or no residual activity, and as juvenile stages are not vulnerable to space spraying, multiple applications are required to prevent the adult population being replaced (Najera 2003; Bonds 2012).

\section{How the intervention might work}

George Macdonald's theory of vectorial capacity can be used to explain the impact of malaria vector control interventions. Vectorial capacity is a theoretical estimate of the intensity of transmission, equivalent to the basic reproduction ratio of a disease. It describes the total number of potentially infectious bites that would eventually arise from all the mosquitoes in a population biting a single perfectly-infectious human on a single day. The RossMacdonald model shows that vectorial capacity is highly sensitive to interventions that target the adult mosquito population, as they cause a reduction in both the ratio of mosquitoes to humans and the probability of mosquito survival (Macdonald 1952; Smith 2012). If effective, space spraying interventions will therefore have a direct impact on the intensity of transmission. Assuming that the number of infections arising in humans is relative to the number of infectious bites received, this will further lead to a reduction in the number of clinical cases of malaria (Smith 2007).

\section{Why it is important to do this review}

The 2017 World Malaria Report shows the declining trend in malaria cases and deaths since the turn of the millennium has begun stalling in recent years, and there is a growing need for additional control methods (WHO 2017a). ITNs and IRS successfully exploit the anthropophilic (human-biting), endophilic (indoor resting), endophagic (indoor biting), and nocturnal behaviours of Africa's most efficient malaria vectors: Anopheles gambiae and Anopheles funestus (Pates 2005; Sinka 2010). In areas of low to moderate transmission, these interventions can be sufficient to reduce parasite prevalence to elimination thresholds, but additional control measures will be required in settings with high transmission or more challenging vector species (Griffin 2010; Chaccour 2016). Space spraying may have a role in reducing transmission in such settings, as it will impact upon those species that are outdoor-biting and therefore more behaviourally resistant to ITNs and IRS. This is of particular interest in the current and future climate, as coverage of ITNs increases and transmission via exophagic and zoophagic vector species becomes more important.

The WHO guidelines for judicious insecticide use state that space spraying may be advisable as an emergency response to malaria epidemics, provided that resources are available for its immediate application, and that the approach has previously had success against the target species (Najera 2003). This is particularly recommended for densely-populated areas with little potential for IRS, such as camps for refugees and displaced people (WHO 2013; WHO 2015).

However, the use of space spraying for malaria control has been limited. This may be due to the difficulty associated with undertaking space spraying at night, when Anopheles mosquitoes are most active, or the view that day-time fogs do not penetrate into the resting sites of Anopheles mosquitoes (Najera 2003). Space spraying may contribute to overall vector control activities in parts of Latin America and Asia, which include targeting against malaria vectors, but due to a shortage of robust evidence there remains widespread uncertainty over whether space spraying has any impact on malaria transmission. Despite its use in a variety of epidemic and emergency situations, there is a perception that space spraying is only performed as a public relations exercise (Najera 2003). Space spraying also carries an expense as it requires both specialized equipment and trained staff, in addition to large quantities of insecticide if implemented on a routine basis.

To achieve a target as ambitious as the eradication of malaria, complete clarity is required about the effectiveness of available control methods. Understanding the impact of space spraying will allow the malaria community, including investors, researchers, and disease-control strategists, to make informed decisions about the allocation of resources and to maximize the benefit of investments.

\section{O B JECTIVES}

The review's primary objective was to evaluate the impact of space spraying on malaria transmission, or the incremental impact when applied in combination with other malaria control methods, in comparison to equivalent conditions with no space spraying intervention.

To guide future evaluations of space spraying, a secondary objective was to identify and summarize the range of space spraying strategies that have been trialled, those which were promising and warrant further evaluation, and those which appear unlikely to warrant further evaluation (for example, if they were not feasible to implement, or were unacceptable to the population).

\section{METHODS}

\section{Criteria for considering studies for this review}

\section{Types of studies}

For our primary objective, we included the following types of studies.

- Randomized controlled trials (RCTs). As the intervention is distributed at a community level, we did not expect to find trials with individual randomization. We included cluster-randomized controlled trials (CRCTs) with:

* the unit of randomization being a cluster;

* evidence of baseline equivalence;

* monitoring of at least one transmission season; and

* at least two clusters per arm.

- Interrupted time series (ITS) designs with:

* a clearly-defined point in time when the intervention occurred; and

* at least three data points before and three after the intervention.

- Randomized cross-over studies with:

* a clearly-defined point in time when the cross-over occurred; and

* monitoring of at least two transmission seasons before and after the cross-over. 
- Controlled before-and-after (CBA) studies with:

* a contemporaneous control group;

* monitoring of at least one transmission season before and after the intervention; and

* at least two sites per treatment arm.

As part of our secondary objective to review a broader range of space-spraying strategies that have been tested, we have also included the following study designs that were considered to provide little or no reliable evidence regarding effects.

- CBA studies with only one site per treatment arm.

- ITS studies with monitoring of at least two time points before and after the intervention.

\section{Types of participants}

Children and adults living in malaria transmission settings.

\section{Types of interventions}

\section{Intervention}

- Interventions that use space spraying of insecticides with the purpose of knocking down and killing adult Anopheles mosquitoes.

- Interventions may include thermal fogging or cold aerosols distributed through pedestrian (hand-held/backpack), ground vehicle, or aerial means.

- Insecticides applied in repetitions, with a minimum of two sprays.

\section{Control}

- Equivalent regions that did not receive the above-named spacespraying interventions.

- Equivalent regions that received space spraying with an alternative public health insecticide.

- The control group must not have received any other malaria cointervention(s) that differed from the intervention arm.

\section{Types of outcome measures}

We included studies that reported any of the following outcomes.

\section{Primary outcomes}

- Incidence: measured as a count per person unit time of (a) infections or (b) new infections, following radical cure to avoid measuring pre-existing infections. We defined infection as any symptom, including fever, with confirmed parasitaemia (by blood smear microscopy or rapid diagnostic test (RDT)).

- Parasite prevalence: the proportion of surveyed individuals with confirmed parasitaemia.

\section{Secondary outcomes}

\section{Epidemiological outcomes}

- All-cause mortality.

- Number of people with severe disease: we used site-specific definitions, provided they included (a) and either (b) or (c): (a) demonstration of parasitaemia by blood smear; (b) symptoms of cerebral malaria including coma, prostration, or multiple seizures; (c) severe, life-threatening anaemia.
- Number of people with uncomplicated clinical malaria episodes: we used site-specific definitions, provided they included (a) demonstration of malaria parasites by either blood smear or RDT, or both; and (b) clinical symptoms including fever detected passively or actively.

\section{Entomological outcomes}

- Entomological Inoculation Rate (EIR): the estimated number of bites by infectious mosquitoes per person per unit time. This is measured using the human biting rate (the number of mosquitoes biting an individual over a stated period, measured directly using human baits or indirectly using light-traps, knockdown catches, baited huts, or other methods of biting rate determination) multiplied by the sporozoite rate.

- Adult mosquito density: measured by a technique previously shown to be appropriate for the vector (measured using human baits, light-traps, knock-down catches, baited huts, or other methods).

- Sporozoite rate.

\section{Adverse events}

Any indicators of adverse events of the intervention, including the following.

- Reports of poisoning in humans due to increased exposure to insecticide.

- Environmental impacts, such as changes to the biodiversity and ecosystem, due to the addition of insecticides.

\section{Search methods for identification of studies}

We attempted to identify all relevant trials, regardless of language or publication status (published, unpublished, in press, and in progress).

\section{Electronic searches}

We searched the following databases on 18 April 2018, using the search terms and strategy described in Appendix 1: the Cochrane Infectious Diseases Group Specialized Register; the Central Register of Controlled Trials (CENTRAL), published in the Cochrane Database of Systematic Reviews (Issue 4 of 12, April 2018); MEDLINE (PubMed, from 1966); Embase (OVID, from 1947); CAB Abstracts (Web of Science, from 1973); and LILACS (BIREME, from 1982). We also searched the WHO International Clinical Trials Registry Platform (www.who.int/ictrp/search/en/), and ClinicalTrials.gov (clinicaltrials.gov/) to identify ongoing trials.

\section{Searching other resources}

\section{Organizations (and pharmaceutical companies)}

We contacted organizations, including the WHO and the Centers for Disease Control and Prevention (CDC), for ongoing and unpublished trials.

\section{Reference lists}

We also checked the reference lists of all included studies for further relevant studies. 


\section{Data collection and analysis}

\section{Selection of studies}

Two review authors (JP and LC) independently screened the titles and abstracts of articles identified by the literature searches for inclusion. We assessed the full-text articles of potentially relevant trials for inclusion, using an eligibility form that was based on our inclusion criteria. We compared included trials and resolved any disagreements by discussion and consensus, with arbitration by a third review author (DM) if necessary. We ensured that we included multiple publications of the same trial only once.

\section{Data extraction and management}

Two review authors (JP and LC) independently extracted information from the included studies using pre-piloted, electronic data extraction forms. The two review authors discussed any differences in the extracted data to reach consensus, and resorted to a third review author (DM) when differences could not be resolved between them. In case of missing data, we attempted to contact the original study author(s) for clarification.

We extracted data on the following.

- Trial design: type of trial; method of participant selection; adjustment for clustering (for cRCTs); sample size; method of blinding of participants and personnel.

- Participants: trial settings and population characteristics; recruitment rates; withdrawal and loss to follow-up.

- Intervention: description of intervention (active ingredient, dose, formulation, droplet diameter, droplet density, ground or aerial spraying method, ULV or cold fogging, frequency and timing of application, size of treated area, buffer zone between clusters, caged-mosquito outcomes); co-interventions; description of control; duration of follow-up; coverage of intervention and access to co-interventions; compliance of intervention and any co-interventions.

- Outcomes: definition of outcome; diagnostic method or surveillance method; passive or active case detection; number of events; number of participants or unit time; statistical power; unit of analysis; incomplete outcomes/missing data.

- Other:

* primary and secondary vector(s) species; vector(s) behaviour (nature, stability, adult habitat, peak biting times, exophilic/endophilic, exophagic/endophagic, anthropophilic/zoophilic); method of mosquito collection(s); phenotypic insecticide resistance (based on WHO definitions if supplementary WHO cylinder assays or CDC bottle bioassays, or both, were performed whilst the trial was running); genotypic insecticide resistance profile (either performed during the trial or if the trial references data from previous studies done on the same local vector population within the previous five years).

* malaria endemicity; eco-epidemiological setting; population proximity and density; Plasmodium species.

For dichotomous outcomes, we extracted the number of participants who experienced each outcome and the number of participants in each treatment group. If the number of participants was not reported, we estimated the treated population using census data. For count data outcomes, we extracted the number of outcomes in the treatment and control groups, and the total person time at risk in each group, or the rate ratio and a measure of variance (for example, standard error). For numerical outcomes we extracted the mean and a measure of variance (standard deviation (SD)).

For CRCTs we intended to record the number of clusters randomized; number of clusters analysed; measure of effect (such as risk ratio, odds ratio, or mean difference) with confidence intervals (Cls) or standard deviations; number of participants; and the intracluster correlation coefficient (ICC) value.

\section{Assessment of risk of bias in included studies}

We intended to independently assess CRCTs for risks of bias using the Cochrane 'Risk of bias' tool, and the five additional criteria listed in Section 16.3.2 of the Cochrane Handbook for Systematic Reviews of Interventions relating specifically to cluster-randomized trials (Higgins 2011). Two review authors (JP and LC) assessed the included non-randomized studies (NRSs) for risks of bias using the Cochrane Effective Practice and Organization of Care (EPOC) 'Risk of bias' tool (Cochrane EPOC 2016). We resolved any discrepancies through discussion or, if necessary, through consultation with a third review author (DM). We classified judgements of risk of bias as either at low, high, or unclear risk of bias.

\section{Measures of treatment effect}

We compared intervention and control data using risk ratios and rate ratios.

For NRSs, we intended to extract adjusted measures of intervention effects that attempted to control for confounding.

As the included ITS studies did not report intervention effect estimates that we could extract, we digitized the presented time series graphs to obtain data sets for each study using the graph digitizing software WebPlotDigitizer (automeris.io/ WebPlotDigitizer). We then imported the data sets for each study into Stata version 14.1 (StataCorp 2017).

We fitted a Poisson regression model that predicted values for our outcomes of interest at the post-intervention time points in the absence of the intervention. Where the population size was reported at different time points within the time series, we included population size as an offset in the model. Where population sizes were not provided and were instead estimated using census data, we assumed that the denominator population would not have changed rapidly over short timescales, and we did not include population size as an offset in the model. The model adjusted for seasonality using a Fourier term and also accounted for overdispersion (Bernal 2017). We hypothesized that if the intervention was effective, it would have two separate effects on the outcome. The first is a step change (defined as the difference between the observed level at the first post-intervention time point and the predicted level at the same time point based on the preintervention trend). The second effect is a slope change (defined as the difference between the post- and pre-intervention slopes) (Ramsay 2003). For the analysis, we treated the step change and the slope change as different outcomes of the intervention. The model included terms for both the step and slope effect of the intervention, and was used to produce estimates of the step and slope rate ratios. We also produced graphs that show the observed data, the trend line fitted by the model, and the point at which the intervention was introduced. 
We assessed autocorrelation for each model by examining the plot of residuals and the partial autocorrelation function. If we had identified autocorrelation we would have adjusted for this using the autoregressive integrated moving average (ARIMA) method, as in the methods of Bernal 2017. However, there was very little evidence of autocorrelation in any of our models.

We used adjusted measures of effect to summarize the treatment effect from all included NRSs. We present all results with their associated $95 \% \mathrm{Cls}$.

\section{Unit of analysis issues}

If we identified CRCTs that had not adjusted for clustering in the analysis, we intended to adjust data before combining them, by multiplying standard errors by the square root of the design effect (Higgins 2011). If the trial did not report the ICC value, we would have estimated the ICC from a similar trial if possible, or by searching external sources for example ICCs, or alternatively, we would not include CRCTs that had not adjusted for clustering in the meta-analysis, but would present results in a separate table.

\section{Dealing with missing data}

In case of missing data, we applied available-case analysis, only including data on the known results. The denominator is the total number of participants who had data recorded for the specific outcome. For outcomes with no missing data, we performed analyses on an intention-to-treat basis. We intended to include all participants randomized to each group in the analyses and to analyse participants in the group to which they were randomized.

\section{Assessment of heterogeneity}

We inspected forest plots for overlapping $\mathrm{Cls}$ and assessed statistical heterogeneity in each meta-analysis using the $\mathrm{I}^{2}$ statistic and $\mathrm{Chi}^{2}$ test values. We regarded heterogeneity as moderate if $\mathrm{I}^{2}$ statistic values were between $30 \%$ to $60 \%$; substantial if they were between $50 \%$ and $90 \%$; and considerable if they were between $75 \%$ and $100 \%$. We regarded a $\mathrm{Chi}^{2}$ test statistic with a $\mathrm{P}$ value greater than 0.10 to indicate statistically significant heterogeneity. We explored clinical and methodological heterogeneity through consideration of the trial populations, methods and interventions, and by visualization of trial results.

\section{Assessment of reporting biases}

If there were 10 or more included trials in each meta-analysis, we intended to investigate reporting biases (such as publication bias) using funnel plots (Harbord 2006). However, we did not identify enough studies suitable for inclusion.

\section{Data synthesis}

We analysed data using Review Manager 5 (RevMan) (RevMan 2014). We intended to pool data from RCTs in a meta-analysis. If we judged NRSs were both reasonably resistant to biases and relatively homogeneous, we combined data across studies using meta-analysis (Taggart 2001). We did not include NRSs in metaanalyses with RCTs. For meta-analysis of CRCTs, if identified, we intended to use the crude or unadjusted effect estimates, while meta-analyses for NRSs used the adjusted measures of effect, as in Section 13.6.1 of the Cochrane Handbook for Systematic Reviews of Interventions (Reeves 2011).
We intended to use a fixed-effect meta-analysis to combine data if heterogeneity was absent, and using a random-effects metaanalysis if considerable heterogeneity was present. However, we decided to use a random-effects meta-analysis based on the consideration of known methodological heterogeneity between the study sites. We synthesized effect estimates for the step rate ratio and slope rate ratio using the generic inverse variance method.

We used the effect estimate for the step rate ratio to estimate the immediate effect (within one post-intervention time point) of space spraying. We used the effect estimate for the slope rate ratio to estimate the effect following 12 months of space spraying. We calculated this by multiplying the risk with no space spraying by the slope rate ratio (the proportion of cases avoided each month) for each of 12 months.

We calculated the lower limit of the $\mathrm{Cl}$ for the risk following 12 months of spraying by multiplying the risk with no space spraying by the slope rate ratio's lower limit of the $95 \% \mathrm{Cl}$ for each of the 12 months. We calculated the upper limit of the $\mathrm{Cl}$ for the risk following 12 months of spraying by multiplying the risk with no space spraying by the slope rate ratio's upper limit of the $95 \% \mathrm{Cl}$ for each of the 12 months.

\section{Subgroup analysis and investigation of heterogeneity}

If heterogeneity was detected between studies, we planned to perform the following subgroup analyses.

- Seasonality of malaria (perennial transmission/seasonal transmission/outbreak or high-risk settings).

- Spray equipment used: ground sprays, i.e. using hand-held or vehicle-mounted equipment, or aerial sprays.

- Time of spraying (between 7 am and $6.59 \mathrm{pm}$ or $7 \mathrm{pm}$ and 6.59 am).

We would have tested differences between subgroups using the $\mathrm{Chi}^{2}$ test, with a $\mathrm{P}$ value of less than 0.05 indicating statistically significant differences between subgroups.

\section{Sensitivity analysis}

If possible, we intended to perform a sensitivity analysis on the primary outcome to see the effect of excluding trials at high risk of bias (for allocation concealment and incomplete outcome data) on overall results.

\section{'Summary of findings' table}

We assessed the certainty of the evidence using the GRADE approach (Guyatt 2011). We rated the certainty of the evidence for each primary and adverse event outcome, as described by Balshem 2011.

- High: we are very confident that the true effect lies close to that of the estimate of the effect.

- Moderate: we are moderately confident in the effect estimate. The true effect is likely to be close to the estimate of the effect.

- Low: our confidence in the effect estimate is limited. The true effect may be substantially different from the estimate of the effect.

- Very low: we have very little confidence in the effect estimate. The true effect is likely to be substantially different from the estimate of effect. 
RCTs start as high-certainty evidence but can be downgraded if there are valid reasons within the following five categories: risk of bias, imprecision, inconsistency, indirectness, and publication bias. Studies can also be upgraded if there is a large effect; a doseresponse effect; and if all plausible residual confounding would reduce a demonstrated effect or would suggest a spurious effect if no effect was observed (Balshem 2011).

\section{RES U LTS}

\section{Description of studies}

\section{Results of the search}

We identified 1743 reports through the initial electronic search. To further restrict the search, we considered only those that contained 'malaria' in either the title or abstract, reducing the total number by 937. We screened all 806 remaining abstracts against the review's inclusion criteria. Of these, we identified 31 unique reports for fulltext screening. To confirm the validity of the post hoc restriction, we checked 94 of the now excluded studies (10\%) against the review criteria, and included none of them. A PRISMA flowchart of the screening process is shown in Figure 2.

Figure 2. PRISMA diagram

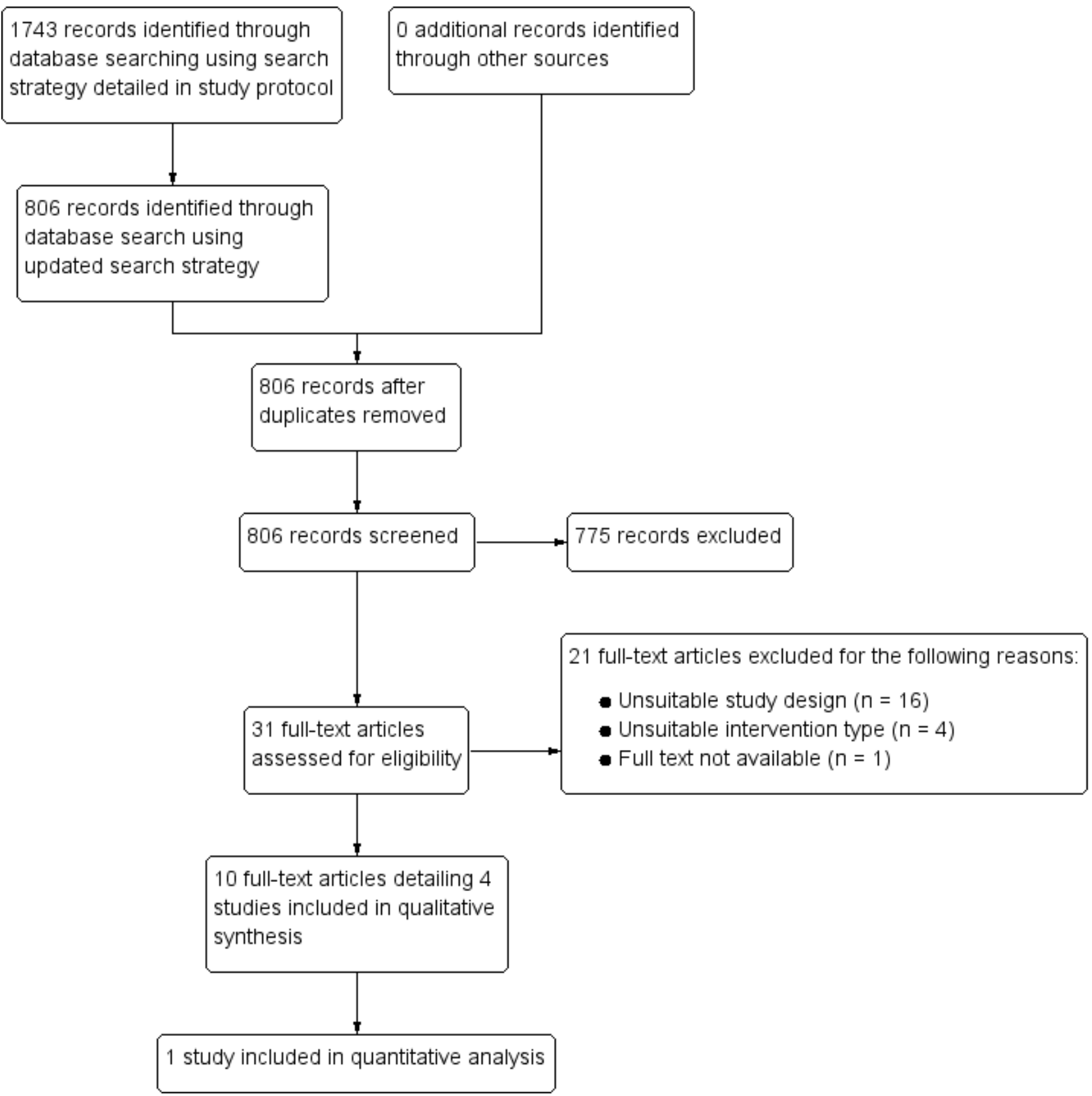


Of the 31 unique reports identified for full-text screening, Eight reports met the inclusion criteria for the primary objective and a further two reports met the criteria for the secondary objective.

\section{Included studies}

\section{Primary objective}

We found no CRCTs for inclusion in this review.

Eight reports detailing two separate NRSs met the inclusion criteria for the review's primary outcome. Both studies met the inclusion criteria for an ITS study. Due to the nature of the intervention, it was applied to all participants within the study areas and outcomes were measured in all inhabitants of the sprayed areas. One study was conducted in the Miragoane Valley on the Southern peninsula of Haiti, with the sprayed area covering a population of 15,106 people (Krogstad 1975). The second study sprayed in three sites in the Thenpennai riverine tract in Tamil Nadu state, India (Tewari 1990). These sites were Pudupettai (Viluppuram district), Vanapuram and Melpallipattu (both Tiruvannamalai district). Due to unique challenges associated with malaria transmission in Sathanur Dam village, Vanapuram, the results from Sathanur Dam were reported separately, providing four distinct study sites.

The population size was reported for the study site of Pudupettai as 1686 people in the years 1979 to 1980 and 2145 people in 1981 to 1982 . However, the population sizes were not reported for the remaining study sites in TIruvannamalai. The number of people covered in each treatment group was therefore estimated using census data. Population sizes for each village in the study were taken from the 2011 Indian population census (COI 2011a). To account for population growth in the 30 years between the study and census dates, the population sizes were adjusted using each of the three decades' growth percentages in the district of Tiruvannamalai (SPC 2007; COI 2011b). This resulted in a reduction of $27.6 \%$ from the 2011 census data for each village. Using this method, the sizes of populations covered were estimated as 4943 (Vanapuram), 6334 (Sathanur Dam) and 5038 (Melpallipattu).

Both studies reported the incidence of malaria cases. Tewari 1990 reported the incidence rate per 1000 at each site over time, with at least a year prior to space spraying implementation reported. The second study, in Haiti, did not report the incidence over time for previous years (Krogstad 1975). Where data were not provided for previous years, it was not possible to model the seasonal trend of malaria incidence in order to estimate the impact of space spraying, and we did not include the results in the meta-analysis.

No studies reported the prevalence of malaria in a time series with sufficient time points, or with a suitable control group, in order to give a contemporaneous comparison. Krogstad 1975 also provided time series data for adult mosquito density, as measured using both updraft UV light-traps and human-baited biting collections.

Both studies used malathion as the active ingredient. One study, Krogstad 1975, used an aerial delivery, spraying an ULV fog at a dose of $4.5 \mathrm{oz} /$ acre from a Beech D-18 aircraft. Spraying was conducted every 10 days. The time of spraying was not reported. The second study, Tewari 1990, used ground-based hand-held spray equipment, with distinct methods in each site. In Pudupettai, ULV fogging was conducted weekly using hand-held sprayers. After six weeks, spraying was conducted only in response to new cases. In Vanapuram (except Sanathur Dam), thermal fogging was conducted fortnightly using hand-held sprayers. Thermal fogging was conducted using jeep-mounted Tifa and handcart-mounted Tiga machines in Melpallipattu (fortnightly) and Sathanur Dam (weekly). In each site, sprays were conducted between $8 \mathrm{pm}$ and 10 pm or $5 \mathrm{am}$ and $7 \mathrm{am}$. Further information of the different methods used in the different sites are detailed in the Characteristics of included studies table.

In both studies, the intervention was implemented and outcomes monitored by a state malaria control programme, with support respectively from US AID (Krogstad 1975) and a local vector control research centre (Tewari 1990). Additionally, IRS was conducted as a continued co-intervention in both studies, and was implemented equally pre- and post-intervention. IRS was conducted with dichlorodiphenyltrichloroethane (DDT) in Haiti and with malathion in India. Tewari 1990 additionally listed larval habitat management and continued case management as co-interventions were also conducted during the study in the Pudupettai district.

\section{Secondary objective}

Two reports detailing a further two studies met the inclusion criteria for the review's secondary objectives. Both studies were conducted as CBA studies, with one cluster per arm.

One study was conducted in El Savador, and used a weekly ULV spray of $5 \%$ pyrethrin with $15 \%$ piperonyl butoxide (Hobbs 1976). The insecticide was delivered using vehicle-mounted equipment, at a dose of 0.002 to $0.0025 \mathrm{lbs} /$ acre, and spraying took place between $6 \mathrm{pm}$ and $7 \mathrm{pm}$ to coincide with peak mosquito bloodseeking activity. The study was conducted by a team from the Central America Research Station (CARS). The report indicated that application of space spraying in this manner was operationally simple, and although the costs of synergized pyrethrins were high, the labour and running costs were low.

The second study was conducted in Malaysia (Seleena 2004). The team conducted a monthly ULV spray of alphacypermethrin, delivered with hand-held spraying equipment at a dose of 2 $\mathrm{g} / 10,000 \mathrm{~m}^{2}$. The spray team comprised villagers, who received staff training, headed by a local public health officer. Although concerns had been expressed about the practicality of groundbased space spraying in such a remote village, this approach was considered to be a practical and inexpensive solution.

Both studies reported the incidence of malaria cases and a measure of the adult mosquito density, which was reported as either the human landing rate (Seleena 2004) or the number of vectors per light-trap per night (Hobbs 1976).

Each of the four included studies is described in the Characteristics of included studies tables, and we have provided a summary of the operational details of space spraying implementation in each study in Table 2.

\section{Excluded studies}

We excluded 21 full-text articles, for the following reasons (see Characteristics of excluded studies):

- 16 reports did not meet the inclusion criteria for study design 
- 4 reports used an intervention that did not meet the inclusion criteria

- 1 report was not available. We considered the study unlikely to be included, as the abstract appeared to describe IRS rather than space spraying

\section{Risk of bias in included studies}

In Figure 3 we give a summary of our judgement of the risks of bias in the two studies included in the primary objective. We have listed individual 'Risk of bias' assessments in the Characteristics of included studies section.

Figure 3. 'Risk of bias' summary: review authors' judgements about each risk of bias item for each included study. We did not assess the risk of bias for Hobbs 1976 or Seleena 2004, as the evidence of the effectiveness of space spraying in these studies has not been presented in this review or included in the analysis.

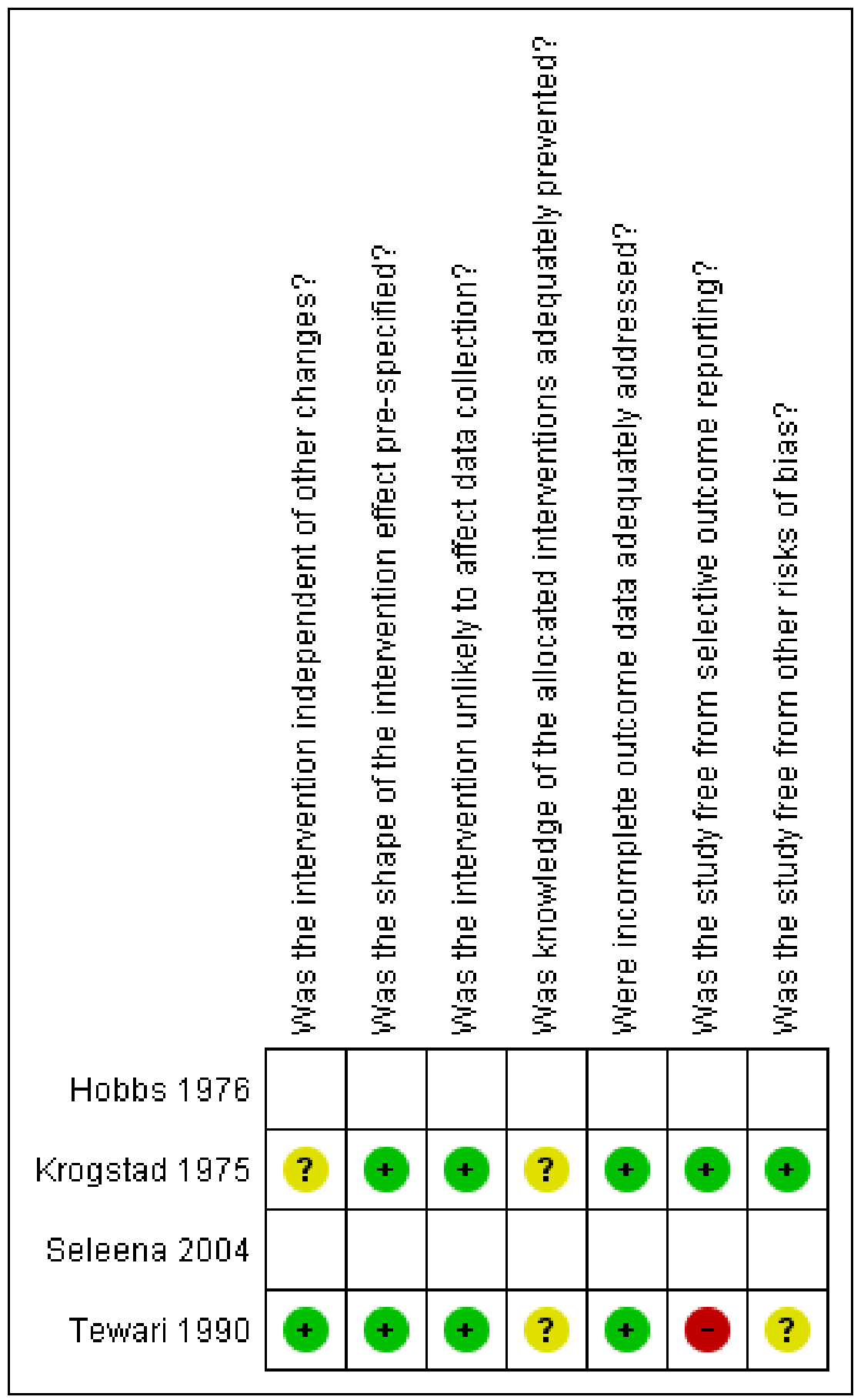

It is unclear in one study whether the intervention was introduced

(Krogstad 1975) . The effect of meteorological conditions is not independently from other changes that may affect the outcomes explored and there is limited information on concurrent control

Insecticide space spraying for preventing malaria transmission (Review) 
measures such as anti-larval measures and chemotherapy. The impact of these activities is therefore hard to measure. The second study confirmed there was no change in co-interventions preand post-space spraying, and that the trend was observed despite normal levels of rainfall (Tewari 1990).

In both studies, the point of analysis was the point that the intervention was introduced, and data collection methods were not altered post-intervention. We rated the studies as low risk of bias for these criteria.

Due to the nature of the intervention, blinding was not conducted in either of the two studies. In both studies, the measurement of incidence depended on self-reporting of fever symptoms, which may be influenced by participant knowledge of the intervention. However, parasitaemia was confirmed by blood smear, and so we judged that there was an unclear risk of bias.

Neither of the studies was at risk of bias from incomplete outcome data. However, we judged Tewari 1990 to have a high risk of bias from selective reporting. Firstly, the study states that 24 villages in Vanapuram were sprayed, but outcome data are presented for only four of them. Secondly, the report states that mosquito density was recorded in Pudupettai, but this outcome is not reported. We also judged this study to be at unclear risk for other potential bias, as it used a variety of spray equipment and insecticide formulations at different times and locations; these are not fully specified and it is not possible to correlate these individual interventions with the outcome data presented.

\section{Effects of interventions}

See: Summary of findings for the main comparison 'Summary of findings' table 1

\section{Incidence}

We present time series plots showing the incidence of malaria following the implementation of space spraying for each study. Figure 4 shows the incidence in the sprayed area in Haiti in comparison to equivalent data from the surrounding unsprayed area (Krogstad 1975). The incidence was reported at 17 preintervention time points and nine post-intervention time points. The red vertical lines indicate the initial implementation and end of the space-spraying intervention, which was timed to coincide with the peak of the transmission season. The study did not report the incidence over time for previous years. Without further information, we cannot say whether this is a typical pattern for this time of year for the intervention group or the control group, and so we have not included the results in the meta-analysis.

Figure 4. Incidence of clinical malaria per 1000 population in the Miragoane Valley of Haiti, March 1972 to February 1973. Incidence in the sprayed zone of the study site is shown in blue; the incidence in the surrounding untreated area is shown in red. The vertical red lines indicate the start and end of the space spraying intervention.

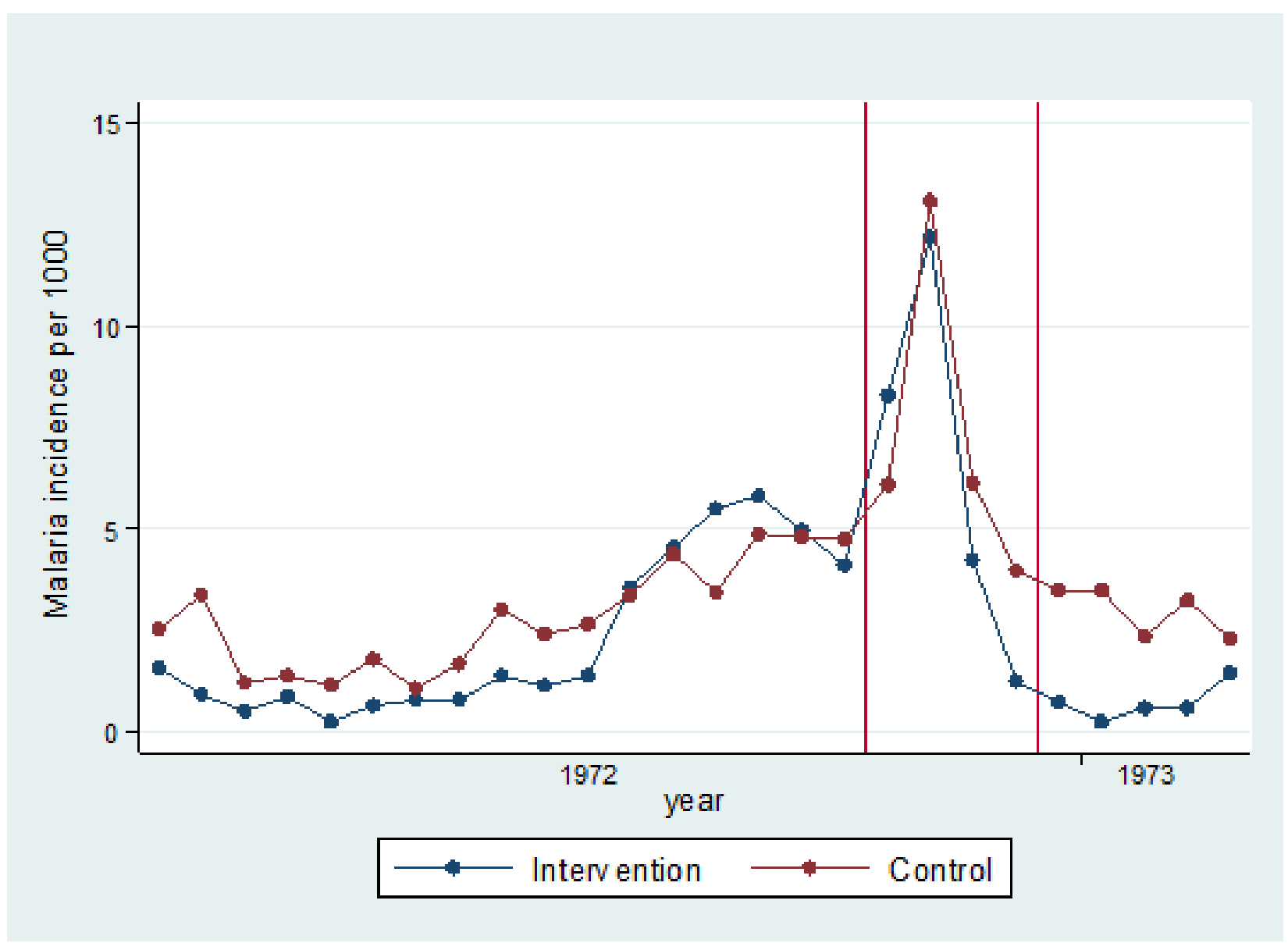

Insecticide space spraying for preventing malaria transmission (Review)

Copyright ( 2018 The Authors. Cochrane Database of Systematic Reviews published by John Wiley \& Sons, Ltd. on behalf of The Cochrane Collaboration. 
We present the observed malaria incidence in the four reported sites of Tewari 1990 in Figures 5 to 8. Figure 5 shows the observed incidence of malaria over time in the study site of Pudupettai. Incidence was reported at 24 pre-intervention and 24 post-intervention time points. Figure 6 shows the incidence in Vanapuram ( 25 pre-intervention and 35 post-intervention time points). Figure 7 shows the incidence in Melpallipattu (31 pre- intervention and 29 post-intervention time points), and Figure 8 shows the incidence in Sathanur Dam (25 pre-intervention and 35 post-intervention time points). In each plot, the observed incidence rates are indicated by blue dots, while the red line demonstrates the trend, adjusted for seasonality. The introduction of space spraying is indicated by a vertical red line.

Figure 5. Number of cases of clinical malaria in Pudupettai, India, reported monthly between 1979 and 1982. The vertical red line indicates the start of the space spraying intervention.

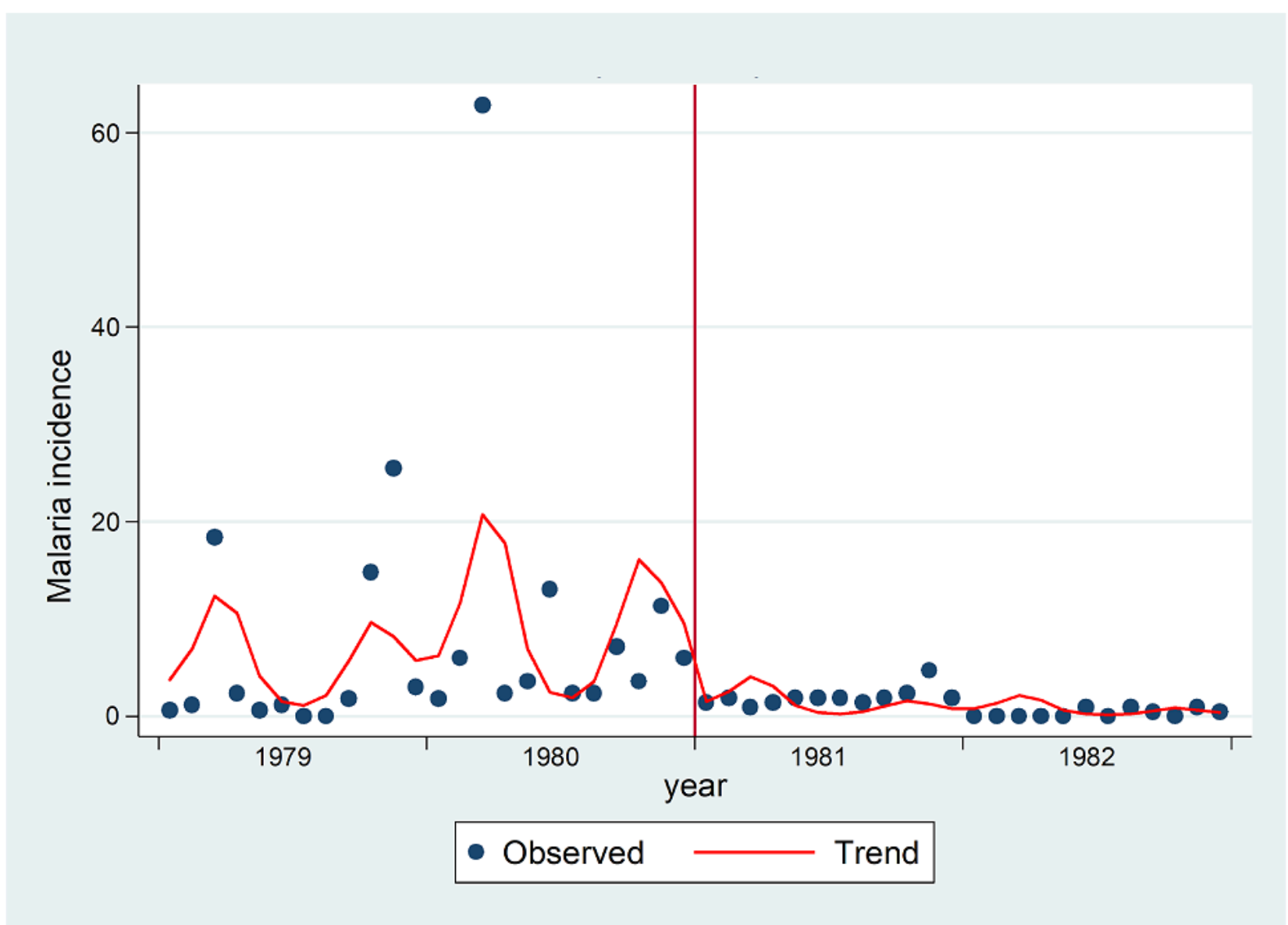


Figure 6. Number of cases of clinical malaria in Vanapuram, India, reported monthly between 1980 and 1984. The vertical red line indicates the start of the space spraying intervention.

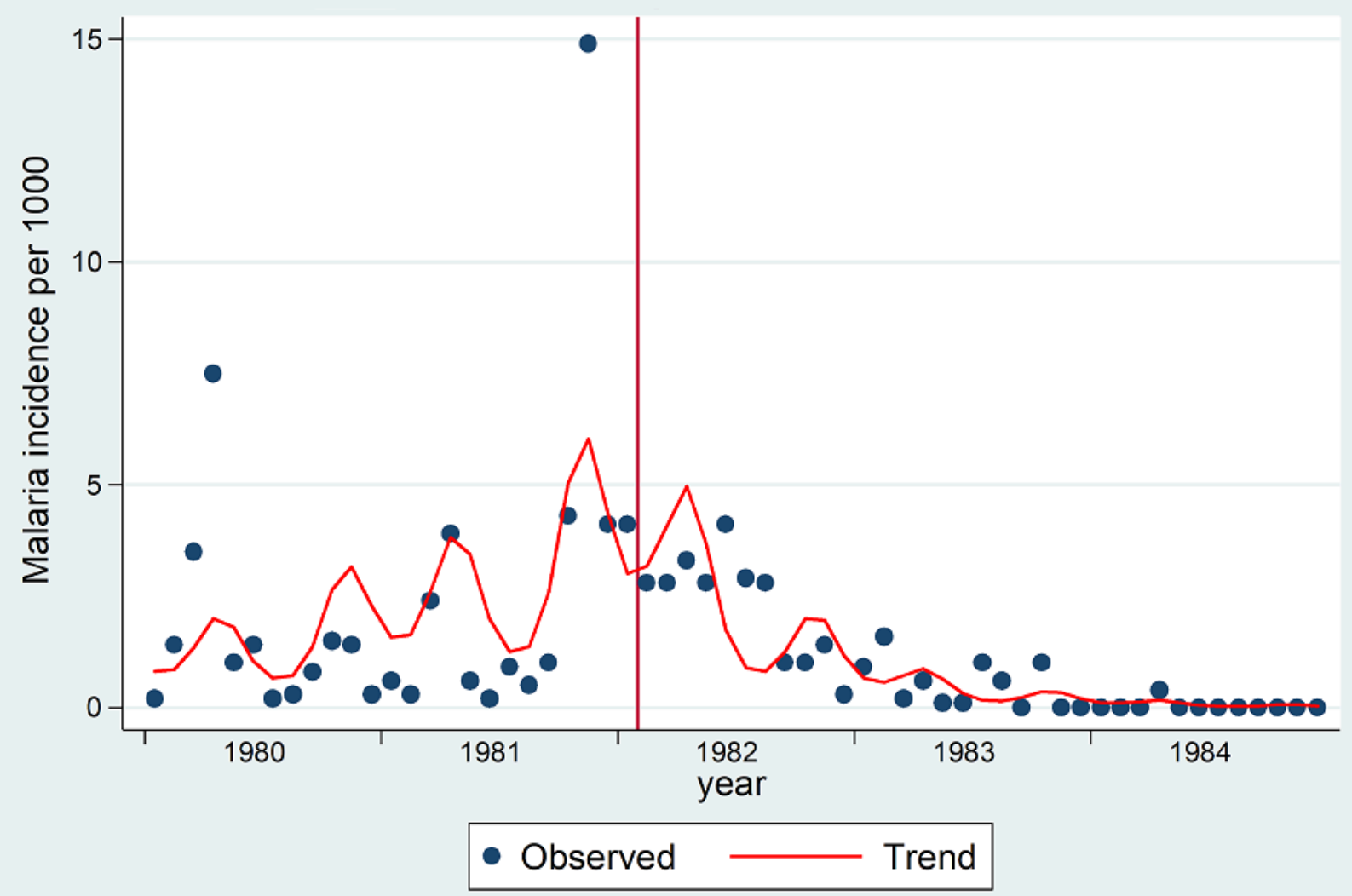


Figure 7. Number of cases of clinical malaria in Melpallipattu, India, reported monthly between 1980 and 1984. The vertical red line indicates the start of the space spraying intervention.

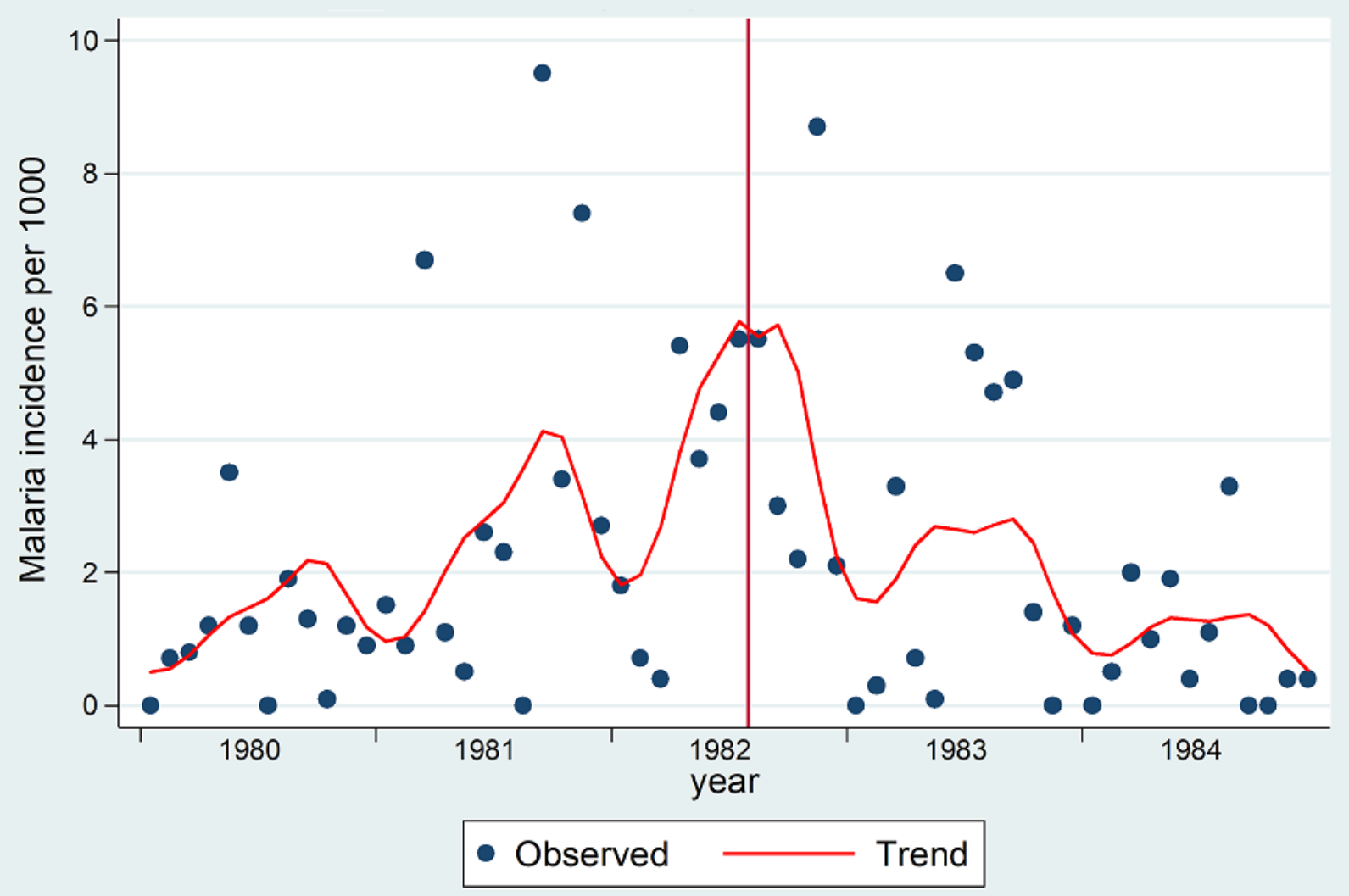


Figure 8. Number of cases of clinical malaria in Sathanur Dam, India, reported monthly between 1980 and 1984. The vertical red line indicates the start of the space spraying intervention.

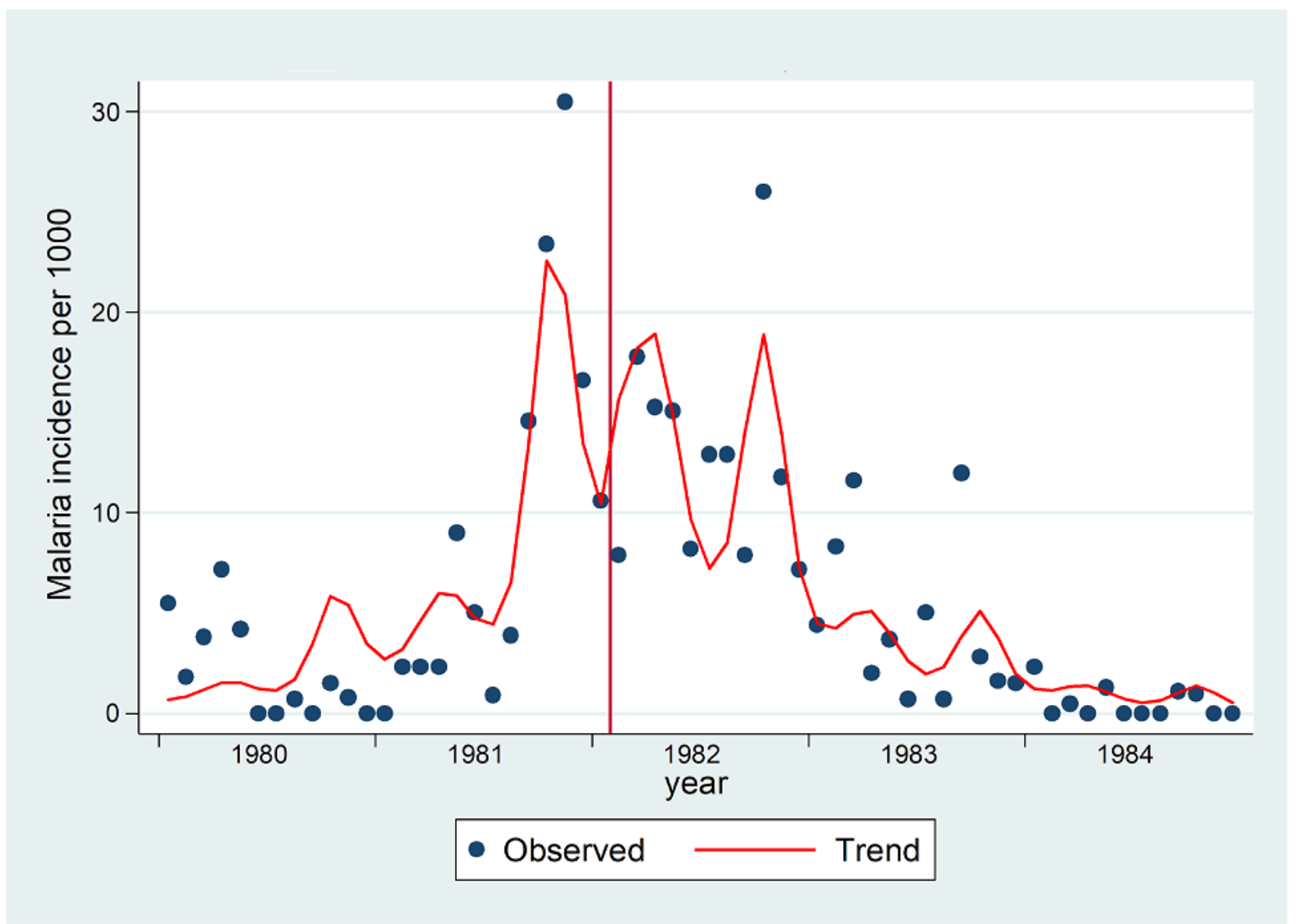

The overall analysis showed that space spraying has no step change (step rate ratio $1.00,95 \% \mathrm{Cl} 0.51$ to 1.92; Analysis 1.1). However, the intervention had an impact on the slope of the trend, so that the proportion of cases reduced by $15 \%$ a month (slope rate ratio 0.85 , $95 \% \mathrm{Cl} 0.79$ to 0.91 ; Analysis 1.2).

\section{Adult mosquito density}

Figure 9 shows the mosquito density measured in the sprayed region in Haiti using updraft UV light-traps (Krogstad 1975).
The outcome was reported at 16 pre-intervention and 19 postintervention time points. Figure 10 shows the density as measured by human-baited biting collections (22 pre-intervention and 18 post-intervention time points). The red vertical lines indicate the initial implementation and end of the space-spraying intervention. The study does not report these outcomes for previous years. We therefore cannot say whether this is a typical pattern for this time of year. 
Figure 9. Mosquito density measured in the sprayed region in Haiti using updraft UV light-traps, March 1972 to February 1973. The initial implementation and end of the space spraying intervention are illustrated by vertical red lines.

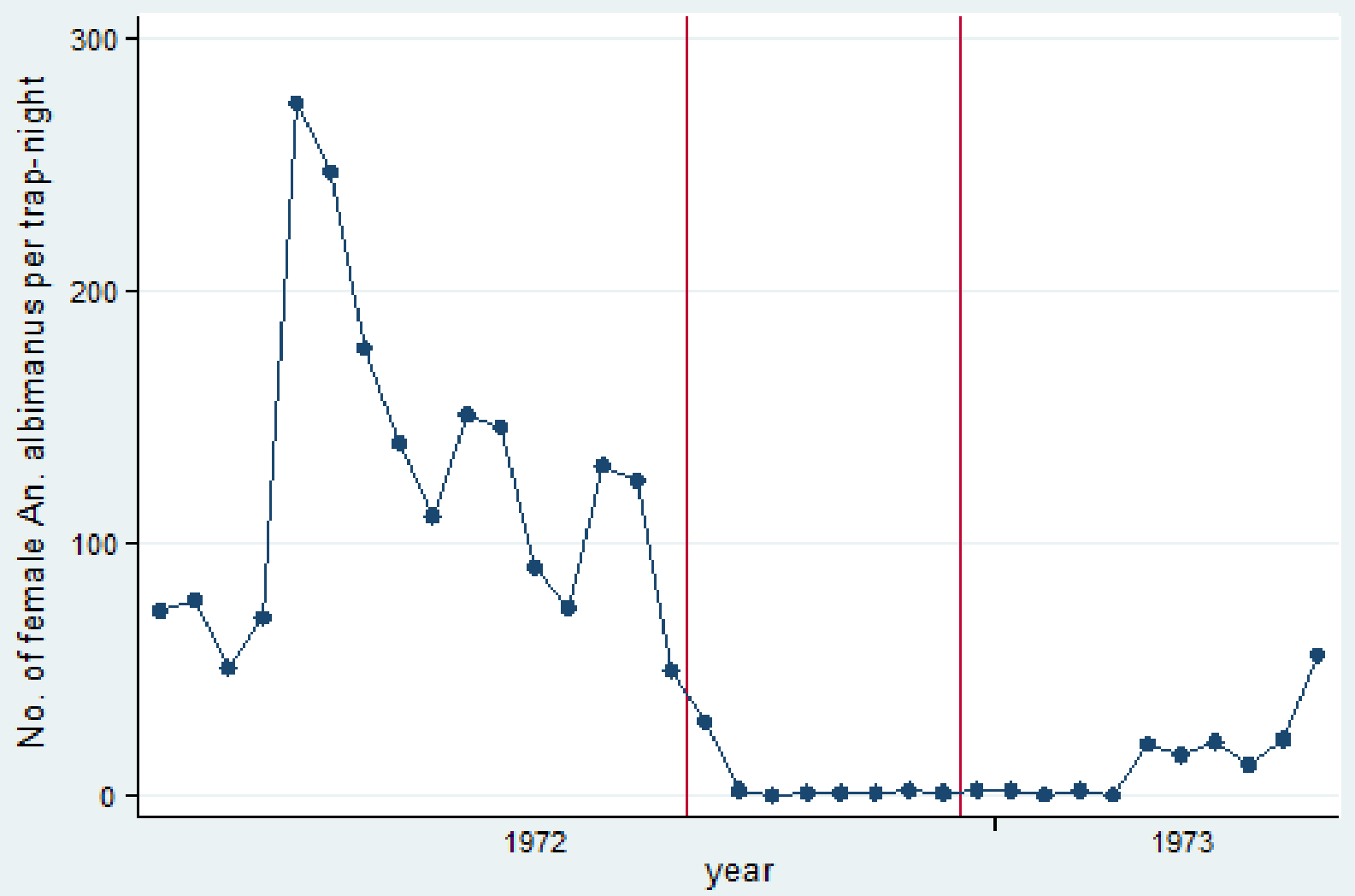


Figure 10. Mosquito density measured as a human biting rate in the sprayed region in Haiti, March 1972 to February 1973. The initial implementation and end of the space spraying intervention are illustrated by vertical red lines.

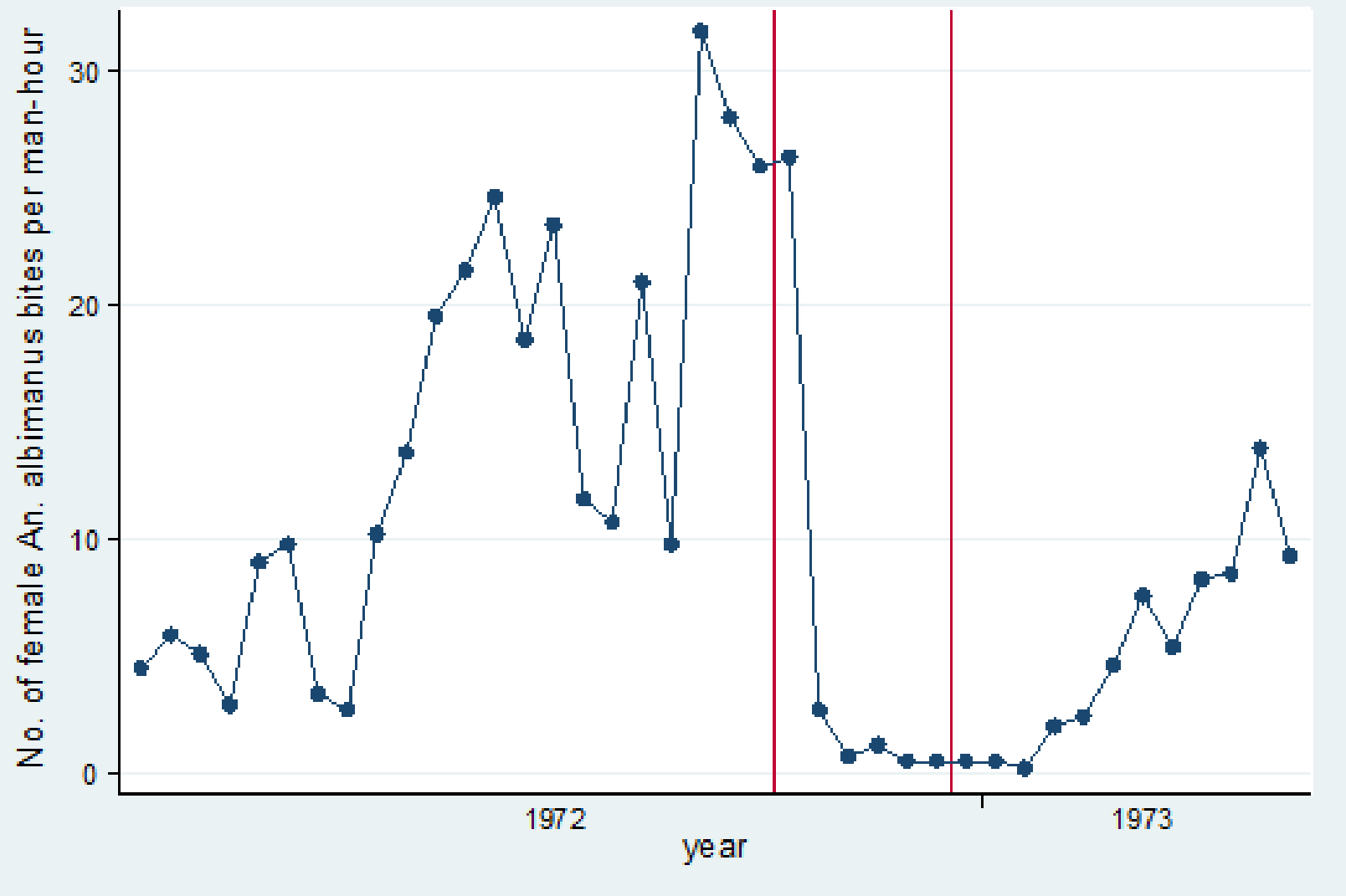

\section{DISCUSSION}

\section{Summary of main results}

See Summary of findings for the main comparison.

Across the included studies, the incidence of malaria was the only outcome reported with a valid comparator that could be used to estimate the impact of space spraying. One study reported the monthly incidence of malaria over a four-year period, with at least one year prior and at least two years post-intervention reported (Tewari 1990). The findings of the study suggest that space spraying had an effect on the incidence of malaria. However, the certainty of the evidence is very low and we cannot be certain that the evidence provided is indicative of the true impact of space spraying on malaria incidence. We do not know if space spraying causes a step change in malaria incidence $(1.00,95 \% \mathrm{Cl} 0.51$ to $1.92,1$ study, very low-certainty evidence). In addition, we do not know if space spraying causes a change in the slope of malaria incidence over time (RR $0.85,95 \% \mathrm{Cl} 0.79$ to $0.91,1$ study, very low-certainty evidence).

\section{Overall completeness and applicability of evidence}

The challenges facing current malaria vector control, including the constraints of IRS and long-lasting insecticide-treated nets (LLINs) for combating residual transmission, and the emergence of pyrethroid resistance, demand the development of an expanded suite of vector control tools to meet increased global aspirations for the elimination and eradication of malaria (Gates 2015). At present, there are doubts about the practicality and effectiveness of space spraying for operational malaria control (Najera 2003). The study included in the quantitative analysis of this review provides limited evidence of the use of space spraying in specific foci of persistent and refractory malaria transmission in India. In these instances, transmission was reduced to a low level, which was subsequently maintained with routine interventions, without the need for regular ongoing space spray applications. However, the findings have limited applicability to global malaria control.

The study interventions included in this assessment were each conducted in Tamil Nadu state, India. The primary vector in the region is Anopheles culicifacies, a late-evening and night-biting mosquito. Although it is predominantly indoor-resting, outdoor resting has also been reported (Sinka 2011). There are at least 150 different malaria vector species and subspecies, and the variation in their habitats and feeding preferences is a major challenge to vector control, often requiring tailored control operations to reflect the local vector species (Ramirez 2009). In addition, local environmental conditions such as climate, vegetation and landscape can significantly impact the longevity of airborne insecticide and its ability to penetrate areas where mosquitoes are active. Due to the indirectness of these data for application to all 
malaria transmission settings, we expect that our estimates may be substantially different from the true magnitude of effect (Guyatt 2011). Driven in part by rapid urbanization and industrialization, the years since the studies were conducted have also seen an increase in time spent by humans outdoors, in outdoor-biting vector behaviour, and increases in vector resistance to insecticides, further reducing our certainty in the estimate of the effect for controlling malaria today (Sharma 1996).

Of the review's two primary outcomes of interest, only malaria incidence data were reported in a manner suitable for evaluation, and we are unable to report on the impact of space spraying on the prevalence of malaria. This is an important outcome that can aid the evaluation process for vector control products. New products are assessed for both efficacy and safety against established standards (WHO 2017b). Adverse event outcomes, such as ecological impacts and increases in insecticide resistance, were not reported in the included studies. However, studies into the nontarget effects of space spraying for dengue control have concluded that the human health risks are most probably negligible (Peterson 2006; Schleier 2009), and that other insects with larger bodies than mosquitoes are not affected by the insecticidal sprays (Boyce 2007).

The studies included in this review were conducted in the 1970s or early 1980 s, before the inauguration of LLINs as a core intervention for the prevention of malaria, and its resulting decrease in malaria incidence (21\%) and malaria-related deaths (29\%) between 2010 and 2015 (WHO 2016a). The studies therefore have limited applicability in the current landscape of global malaria control. As ensuring universal coverage with LLINs or IRS for all people at risk of malaria forms Pillar 1 of the Global Technical Strategy for Malaria, there is a question about the effectiveness of space spraying as a complementary measure to LLINs that remains unanswered by the evidence in this review (WHO 2016a).

\section{Certainty of the evidence}

In the GRADE approach to assessing the certainty of evidence, RCTs are considered to provide high-certainty evidence, assuming they are free from important limitations and bias. Due to the inherent biases in the design of NRSs, evidence provided by ITS studies, such as those reported here, is considered to be of low certainty, even without further limitations (Balshem 2011). We have further downgraded the certainty of our findings for several reasons.

Firstly, we rated the included studies at serious risk of bias. In particular, we considered the risk of selective reporting and the lack of clarity over the independence of the intervention likely to lower confidence in the estimate of the effect. We also downgraded the certainty for serious indirectness due to the restricted range of included studies and the substantial differences in effectiveness that may be expected in other malaria transmission settings with different environments and primary vector species, as described above (Guyatt 2011).

We also judged the certainty of the estimate of the step rate ratio to be at serious risk of imprecision, as the $\mathrm{Cl}$ for the estimate included both a sizeable increase and a decrease in the incidence trend of malaria. Overall, we graded the certainty of the evidence as very low, so that we have very little confidence in the effect estimates. We present full details of the GRADE assessment in the Summary of findings for the main comparison.

\section{Potential biases in the review process}

One potential source of bias in the review process was the decision to include NRSs, which are themselves likely to contain greater biases than randomized trials. The results from such studies should therefore be interpreted with caution. To account for this, we used an adapted 'Risk of bias' tool including extra criteria for issues specific to NRSs, and we have downgraded the certainty of our overall estimates of the effect. A risk to the complete collation of studies meeting the inclusion criteria is that we could not retrieve a potentially relevant study, although we considered it unlikely to be included from the title and abstract screening stage. Regarding the analysis, the exact number of cases per time point was not reported in a table or the text, which required us to estimate the figures used in the review analysis using a plot digitizer. This may introduce small inaccuracies. In addition, as treated population sizes were not reported for each site, we had to estimate the population sizes in included villages using census data which were adjusted for population growth. However, these inaccuracies are not expected to lead to over- or under-estimation of malaria incidence that is differential between pre- and post-intervention timepoints. Finally, our model identified an upward pre-intervention trend in malaria incidence in the absence of space spraying in four out of the five study areas. It is possible that in some of these cases the second pre-intervention year had a higher incidence than the first, due to chance. With the analysis methods used in this review, this would result in an inaccurate estimation of the pre-intervention slope and consequent overestimation of the post-intervention effect. Access to data covering more years would improve our confidence in the estimates of effect.

\section{Agreements and disagreements with other studies or reviews}

To the best of our knowledge, this is the first systematic review to evaluate the impact of space spraying on malaria transmission. However, the conclusions are similar to those in a review of space spraying's impact on dengue transmission. As in our review, Esu 2010 used reduced thresholds for study design inclusion criteria, due to concerns about identifying an adequate number of robust studies. Only one study, which was confounded by co-interventions and lacking a control group, reported the impact on dengue incidence. This finding further highlights the lack of high-quality studies that have been conducted to assess the effectiveness of space spraying for disease control, and the need for more robust evidence to support decision-making on space spraying implementation.

\section{AUTHORS' CONCLUSIONS}

\section{Implications for practice}

Evidence-based policy-making is an imperative process for the development of vector control global guidelines. This review identifies an absence of evidence of space spraying's impact on malaria prevalence, and we are very uncertain about the estimate of the effect on malaria incidence. Consequently, there is an insufficient evidence base for policy-makers to adjudge whether or not space spraying has an impact on malaria morbidity.

\section{Implications for research}

This review highlights the lack of well-designed trials of space spraying as a malaria prevention tool. Common issues surrounding 
trial designs included a lack of a contemporaneous control group, or study arms consisting of one cluster only. Trials identified in this review often had unclear descriptions of the delivery of co-interventions, particularly IRS and larval source management. It is important that any future research adequately reports on and controls for coverage of these interventions. In order to demonstrate value for public health, future trials should report on epidemiological outcomes in addition to entomological outcomes. Wilson 2015 provides further guidance on improving the design and reporting of vector control trials to meet the demands of evidencebased policy making.

\section{ACKN OWLEDGEMENTS}

The Academic Editor of this review is Professor Mical Paul.
JP, LC, and MR are supported by the Research, Evidence and Development Initiative (READ-It) project. READ-It and the editorial base of the Cochrane Infectious Diseases Group are funded by UK aid from the UK government for the benefit of low- and middle-income countries (project number 300342-104). The views expressed do not necessarily reflect the UK government's official policies.

This work was partly supported through a grant from the Global Malaria Programme, WHO.

We are indebted to the mentorship of Professor Paul Garner, CIDG Co-ordinating Editor. 


\section{R E F E R E N C E S}

\section{References to studies included in this review}

Hobbs 1976 \{published data only\}

Hobbs JH. A trial of ultra-low volume pyrethrin spraying as a malaria control measure in El Salvador. Mosquito News 1976;36(2):132-7.

\section{Krogstad 1975 \{published data only\}}

Eliason DA, Joseph VR, Karam J. A prospective study of the effects of ultralow volume (ULV) aerial application of malathion on epidemic Plasmodium falciparum malaria: I Study design and perspective. American Journal of Tropical Medicine and Hygiene 1975;24(2):183-7.

Eliason DA, Joseph VR, Solis M, Taylor RT, McLean RG, Krogstad DJ. The impact of ULV malathion on Anopheles albimanus populations and epidemic Plasmodium falciparum malaria in Haiti. Ninth International Congress on Tropical Medicine and Malaria. Athens 14 - 21 October 1973. Volume 1. Abstracts of invited papers. 1973; Vol. 1:254.

* Krogstad DJ, Joseph VR, Newton LH. A prospective study of the effects of ultralow volume (ULV) aerial application of malathion on epidemic Plasmodium falciparum malaria: IV Epidemiological impacts. American Journal of Tropical Medicine and Hygiene 1975;24(2):199-205.

McClean R, Spillane J, Miles J. A prospective study of the effects of ultralow volume (ULV) aerial application of malathion on epidemic Plasmodium falciparum malaria: III Ecological aspects. American Journal of Tropical Medicine and Hygiene 1975;24(2):193-8.

Taylor RT, Solis M, Weathers DB, Taylor JW. A prospective study of the effects of ultralow volume (ULV) aerial application of malathion on epidemic Plasmodium falciparum malaria: II Entomological and operational aspects. American Journal of Tropical Medicine and Hygiene 1975;24(2):188-92.

\section{Seleena 2004 \{published data only\}}

Seleena P, Lee HL, Chooi KH, Junaidih S. Space spraying of bacterial and chemical insecticides against Anopheles balabacensis Baisas for the control of malaria in Sabah, East Malaysia. Southeast Asian Journal of Tropical Medicine and Public Health 2004;35(1):68-78.

Tewari 1990 \{published data only\}

Mani TR, Rajendran R, Sarangapani TD, Tewari SC, Narayanasamy G, Devaputra M, et al. Evaluation of malathion space-spray as a supplementary control measure against Anopheles culicifacies Gile. Indian Journal of Medical Research 1987;86:31-40.

Narayanasamy G, Appavoo NC, Reuben R, Kapali V. Ultra low volume (ULV) malathion application as a supplementary malaria control measure in two villages of South Arcot district, Tamil Nadu. Indian Journal of Malariology 1989;26(1):19-24.

* Tewari SC, Piruthivi V, Mani TR, Rajendran R, Hiriyan J, Joseph AS, et al. Space-spraying with malathion as a supplementary measure for operational malaria control. Indian Journal of Medical Research 1990;91:151-8.

\section{References to studies excluded from this review}

\section{Adam 1964 \{published data only\}}

Adam JP, Progent A, Demellier M. Present organisation and problems of malaria control at Brazzaville (Congo Republic). Study of the susceptibility of A. gambiae to various insecticides. Medecine Tropicale 1964;24(4):437-66.

Afridi 1962 \{published data only\}

Afridi MK. Official history of the Indian Armed Forces in the second world war 1939-45. Medical services: preventive medicine (nutrition, malaria control and prevention of diseases). Part II. Malaria control. Indian Journal of Malariology 1962;16(4):393-503.

\section{Bown 1981 \{published data only\}}

Bown DN, Knudsen AB, Chukwuma FO, Arata AA, Ezike VI, Iwuala MOE, et al. Indoor and outdoor ULV applications of malathion for the extended control of Anopheles and Aedes species in wooded rural communities in eastern Nigeria. Mosquito News 1981;41(1):136-42.

\section{Cáceres G 2013 \{published data only\}}

Cáceres G JL. Malaria incidence record in Venezuela Record de incidencia malarica en Venezuela. Boletin de Malariologia y Salud Ambiental 2013;53(1):88-98.

\section{De Andrade 1986 \{published data only\}}

De Andrade JC, Anjos CF, Wanderley DM, Alves MJ, De Campos PC. The malaria focus in the state of Sao Paulo (Brazil). Revista de Saude Publica 1986;20(4):323-36.

\section{Escudie 1963 \{published data only\}}

Escudie E, Sales P. Initial field studies in Uppper Volta with residual dichlorvos. IV. malarial study. Bulletin of the World Health Organization 1963;29:247-9.

Funckes AJ, Miller S, Hayes WJ Jr. Initial field studies in Uppper Volta with residual dichlorvos residual fumigant as a malaria eradication technique. 3. Toxicological evaluation. Bulletin of the World Health Organization 1963;29:243-6.

Mathis W, St Cloud A, Eyraud M, Miller S, Hamon J. Initial field studies in Uppper Volta with residual dichlorvos residual fumigant as a malaria eradication technique. 2. Entomological evaluation. Bulletin of the World Health Organization 1963;29:237-41.

Quarterman KD, Lotte M, Schoof HF. Initial field studies in Uppper Volta with residual dichlorvos residual fumigant as a malaria eradication technique. 1. General considerations. Bulletin of the World Health Organization 1963;29:231-5.

Schoof HF, Mathis W, Taylor RT, Brydon HW, Goodwin WJ. Studies with dichlorvos residual fumigant as a malaria 
eradication technique in Haiti. I. Operational studies. American Journal of Tropical Medicine and Hygiene 1966;15(5):661-9.

Stein WJ, Miller S, Fetzer LE Jr. Studies with dichlorvos residual fumigant as a malaria eradication technique in Haiti. 3.

Toxicological studies. American Journal of Tropical Medicine and Hygiene 1966;15(5):672-5.

\section{Harper 1947 \{published data only\}}

Harper PA, Lisansky ET, Sasse BE, Downs WG. Malaria and other insect-borne diseases in the South Pacific campaign, 1942-1945. American Journal of Tropical Medicine 1947;s1-27(3):1-67.

\section{Mason 1977 \{published data only\}}

Mason J, Hobbs J. Malaria field studies in a high-incidence coastal area of El Salvador, C.A. Bulletin of the Pan-American Health Organization 1977;11(1):17-30.

\section{Prasad 1992 \{published data only\}}

Prasad RN, Virk KJ, Sharma T, Dutta GD. Malaria epidemic in Baniyani village, District Farrukhabad (U.P.). Indian Journal of Malariology 1992;29(4):219-24.

\section{Shalli 1970 \{published data only\}}

Shalli AA. Application of malathion in southern region Basrah Liwa (Province) as an insecticide. Bulletin of Endemic Diseases 1970;12(1):53-60.

\section{Sharma 1986 \{published data only\}}

Sharma VP, Sharma GK, Ansari MA, Mittal PK, Razdan RK, Batra CP. Impact of malathion thermal fogging on mosquito populations in Delhi and its place in malaria control. Indian Journal of Malariology 1986;23(1):65-7.

\section{Strickman 2001 \{published data only\}}

Strickman D, Miller ME, Lee KW, Kim HC, Wirtz RA, Perich M, et al. Successful entomological intervention against Anopheles sinensis, limiting transmission of Plasmodium vivax to American soldiers in the Republic of Korea. Korean Journal of Entomology 2001;31(3):189-95.

\section{Turner 1977 \{published data only\}}

Turner DA. Ultra-low-volume ground aerosol as a supplementary anti-vector measure in the Solomon Islands malaria eradication programme. Mosquito News 1977;37(4):624-8.

\section{Viswanathan 1950 \{published data only\}}

Viswanathan DK. Malaria and Its Control in Bombay State. Poona: Connaught House, 1950.

\section{Warren 1985 \{published data only\}}

Warren M, Spencer HC, Churchill C. Assessment of exposure to organophosphate insecticides during spraying in Haiti: Monitoring of urinary metabolites and blood cholinesterase levels. Bulletin of the World Health Organization 1985;63(2):353-60.

\section{Zapata 1953 \{published data only\}}

Zapata LB. Studies on the incidence of malaria in Lloro [German]. Bogota: Cienc. Afines, 1953:195-228.

\section{Additional references}

\section{Adam 2013}

Adam Y, Cecchi G, Kgori PM, Marcotty T, Mahama Cl, Abavana M, et al. The sequential aerosol technique: a major component in an integrated strategy of intervention against riverine tsetse in Ghana. PLoS Neglected Tropical Diseases 2013;7(3):e2135. [DOI: 10.1371/journal.pntd.0002135]

\section{Balshem 2011}

Balshem H, Helfand M, Schünemann HJ, Oxman AD, Kunz R, Brozek J, et al. GRADE guidelines: 3 . Rating the quality of evidence. Journal of Clinical Epidemiology 2011;64(4):401-6. [DOI: 10.1016/j.jclinepi.2010.07.015]

\section{Bernal 2017}

Bernal JL, Cummins S, Gasparrini A. Interrupted time series regression for the evaluation of public health interventions: a tutorial. International Journal of Epidemiology 2017;46(1):348-55.

\section{Bonds 2012}

Bonds JA. Ultra-low-volume space sprays in mosquito control: a critical review. Medical and Veterinary Entomology 2012;26(2):121-30. [DOI: 10.1111/j.1365-2915.2011.00992.x]

\section{Boyce 2007}

Boyce WM, Lawler SP, Schultz JM, McCauley SJ, Kimsey LS, Niemela MK, et al. Nontarget effects of the mosquito adulticide pyrethrin applied aerially during a West Nile virus outbreak in an urban California environment. Journal of the American Mosquito Control Association. 2007;23(3):335-9.

\section{Chaccour 2016}

Chaccour C, Killeen GF. Mind the gap: residual malaria transmission, veterinary endectocides and livestock as targets for malaria vector control. Malaria Journal 2016;15:24. [DOI: 10.1186/s12936-015-1063-y]

\section{Cochrane EPOC 2016}

Cochrane Effective Practice, Organisation of Care (EPOC). Suggested risk of bias criteria for EPOC reviews. EPOC Resources for review authors. Available at: epoc.cochrane.org/ epoc-specific-resources-review-authors (accessed 31 May 2017).

\section{COI 2011a}

Census Organization of India. Population Census 2011. www.census2011.co.in/ 2011 (accessed 3 August 2018).

\section{COI 2011b}

Census Organization of India. Provisional population traits: Rural-Urban distribution, Tamil Nadu series 34. censusindia.gov.in/2011-prov-results/paper2/data_files/ tamilnadu/Tamil\%20Nadu_PPT2_Volume1_2011.pdf 2011 (accessed 3 August 2018).

\section{Epelboin 2012}

Epelboin L, Hanf M, Dussart P, Ouar-Epelboin S, Djossou F, Nacher $\mathrm{M}$, et al. Is dengue and malaria co-infection more severe than single infections? A retrospective matched-pair 
study in French Guiana. Malaria Journal 2012;11:142. [DOI: 10.1186/1475-2875-11-142]

\section{Esu 2010}

Esu E, Lenhart A, Smith L, Horstick O. Effectiveness of peridomestic space spraying with insecticide on dengue transmission; systematic review. Tropical Medicine \& International Health 2010;15(5):619-31. [DOI: 10.1111/ j.1365-3156.2010.02489.x]

\section{Gates 2015}

Gates B, Chambers R. From Aspiration to Action-What Will it Take to End Malaria. Gates Foundation, 2015.

\section{Griffin 2010}

Griffin JT, Hollingsworth TD, Okell LC, Churcher TS, White M, Hinsley W, et al. Reducing Plasmodium falciparum malaria transmission in Africa: a model-based evaluation of intervention strategies. PLoS Medicine 2010;7(8):e1000324. [DOI: 10.1371/journal.pmed.1000324]

\section{Guyatt 2011}

Guyatt GH, Oxman AD, Schünemann HJ, Tugwell P, Knottnerus A. GRADE guidelines: a new series of articles in the Journal of Clinical Epidemiology. Journal of Clinical Epidemiology 2011;64(4):380-2.

\section{Harbord 2006}

Harbord RM, Egger M, Sterne JA. A modified test for smallstudy effects in meta-analyses of controlled trials with binary endpoints. Statistics in Medicine 2006;25(20):3443-57.

\section{Higgins 2011}

Higgins JP, Altman DG, Gøtzsche PC, Jüni P, Moher D, Oxman AD, et al. The Cochrane Collaboration's tool for assessing risk of bias in randomised trials. BMJ 2011;343:d5928. [DOI: 10.1136/bmj.d5928]

\section{Lengeler 2004}

Lengeler $\mathrm{C}$. Insecticide-treated bed nets and curtains for preventing malaria. Cochrane Database of Systematic Reviews 2004, Issue 2. [DOI: 10.1002/14651858.CD000363.pub2]

\section{Macdonald 1952}

Macdonald G. The analysis of the sporozoite rate. Tropical Disease Bulletin 1952;49(6):569-86.

\section{Murray 2012}

Murray CJ, Vos T, Lozano R, Naghavi M, Flaxman AD, Michaud C, et al. Disability-adjusted life years (DALYs) for 291 diseases and injuries in 21 regions, 1990-2010: a systematic analysis for the Global Burden of Disease Study 2010. Lancet 2012;380(9859):2197-223. [DOI: 10.1016/ S0140-6736(12)61689-4]

\section{Najera 2003}

Najera JA, Zaim M, World Health Organization. Decision making criteria and procedures for judicious use of insecticides (WHO Communicable Disease Control, Prevention and Eradication: WHO Pesticide Evaluation Scheme). 2003. apps.who.int/iris/bitstream/10665/67365/1/
WHO_CDS_WHOPES_2002.5_Rev.1.pdf. Geneva: World Health Organization, (accessed 31 May 2017).

\section{Pates 2005}

Pates H, Curtis C. Mosquito behavior and vector control. Annual Review of Entomology 2005;50:53-70.

\section{Peterson 2006}

Peterson RK, Macedo PA, Davis RS. A human-health risk assessment for West Nile virus and insecticides used in mosquito management. Environmental Health Perspectives 2006;114(3):366.

\section{Pluess 2010}

Pluess B, Tanser FC, Lengeler C, Sharp BL. Indoor residual spraying for preventing malaria. Cochrane Database of Systematic Reviews 2010, Issue 4. [DOI: 10.1002/14651858.CD006657.pub2]

\section{Ramirez 2009}

Ramirez JL, Garver LS, Dimopoulos G. Challenges and approaches for mosquito targeted malaria control. Current Molecular Medicine 2009;9(2):116-30.

\section{Ramsay 2003}

Ramsay CR, Matowe L, Grilli R, Grimshaw JM, Thomas RE. Interrupted time series designs in health technology assessment: lessons from two systematic reviews of behaviour change strategies. International Journal of Health technology Assessment in Health Care 2003;19:613-23.

\section{Reeves 2011}

Reeves BC, Deeks JJ, Higgins JPT, Wells GA, on behalf of the Cochrane Non-Randomised Studies Methods Group. Chapter 13: Including non-randomized studies. In: Higgins JP, Green S, editor(s). Cochrane Handbook for Systematic Reviews of Interventions Version 5.1.0 (updated March 2011). The Cochrane Collaboration, 2011. Available from handbook.cochrane.org.

\section{RevMan 2014 [Computer program]}

Nordic Cochrane Centre, The Cochrane Collaboration. Review Manager 5 (RevMan 5). Version 5.3. Copenhagen: Nordic Cochrane Centre, The Cochrane Collaboration, 2014.

\section{Schleier 2009}

Schleier JJ, Macedo PA, Davis RS, Shama LM, Peterson RK. A two-dimensional probabilistic acute human-health risk assessment of insecticide exposure after adult mosquito management. Stochastic Environmental Research and Risk Assessment 2009;23(5):555-63.

\section{Sharma 1996}

Sharma VP. Re-emergence of malaria in India. Indian Journal of Medical Research 1996;103:26-45.

\section{Sinka 2010}

Sinka ME, Bangs MJ, Manguin S, Coetzee M, Mbogo CM, Hemingway J, et al. The dominant Anopheles vectors of human malaria in Africa, Europe and the Middle East: occurrence data, distribution maps and bionomic précis. Parasites \& Vectors 2010;3:117. [DOI: 10.1186/1756-3305-3-117] 


\section{Sinka 2011}

Sinka ME, Bangs MJ, Manguin S, Chareonviriyaphap T, Patil AP, Temperley WH, et al. The dominant Anopheles vectors of human malaria in the Asia-Pacific region: occurrence data, distribution maps and bionomic précis. Parasites \& Vectors 2011;4(1):89.

\section{Smith 2007}

Smith DL, McKenzie FE, Snow RW, Hay SI. Revisiting the basic reproductive number for malaria and its implications for malaria control. PLoS Biology 2007;5(3):e42. [DOI: 10.1371/ journal.pbio.0050042]

\section{Smith 2012}

Smith DL, Battle KE, Hay SI, Barker CM, Scott TW, McKenzie FE. Ross, Macdonald, and a theory for the dynamics and control of mosquito-transmitted pathogens. PLoS Pathogens 2012;8(4):e1002588.

\section{SPC 2007}

State Planning Commision, Tamil Nadu. Tiruvannamalai district Human Development Report 2007. www.in.undp.org/content/ dam/india/docs/hdr_tiruvannamalai_2007_full_report.pdf 2007 (Accessed 03 August 2018).

\section{StataCorp 2017 [Computer program]}

College Station, TX: StataCorp LLC. Stata Statistical Software. Version Release 15. College Station, TX: StataCorp LLC, 2017.

\section{Taggart 2001}

Taggart DP, D'Amico R, Altman DG. Effect of arterial revascularisation on survival: a systematic review of studies comparing bilateral and single internal mammary arteries. Lancet 2001;358(9285):870-5.

\section{WHO 2003}

World Health Organization. Space Spray Application of Insecticides for Vector and Public Health Pest Control: A Practitioner's Guide (Communicable Disease Control, Prevention and Eradication: WHO Pesticide Evaluation Scheme). apps.who.int/iris/bitstream/10665/68057/1/ WHO_CDS_WHOPES_GCDPP_2003.5.pdf. World Health Organization, 2003 (accessed 31 May 2017).

\section{WHO 2013}

World Health Organization. Malaria Control in Humanitarian Emergencies - An Inter-Agency Field Handbook. 2nd Edition. World Health Organization, 2013. [ISBN: 978924154865 6]

\section{CHARACTERISTICS OF STUDIES}

Characteristics of included studies [ordered by study ID]

\section{WHO 2015}

World Health Organization. Global Technical Strategy for Malaria 2016-2030. apps.who.int/iris/bitstream/ handle/10665/176712/9789241564991_eng.pdf. World Health Organization, (accessed 31 May 2017).

\section{WHO 2016a}

World Health Organization. World Malaria Report 2016. www.who.int/malaria/publications/world-malaria-report-2016/ report/en/. World Health Organization, (accessed 31 May 2017).

\section{WHO 2016b}

World Health Organization. WHO recommended insecticides for space spraying against mosquitoes. Updated 5 February 2016. origin.who.int/neglected_diseases/vector_ecology/vectorcontrol/Space_Spray_products_February_2016.pdf (accessed 6 October 2018).

\section{WHO 2017a}

World Health Organization. World Malaria Report 2017. apps.who.int/iris/bitstream/ handle/10665/259492/9789241565523-eng.pdf?sequence=1. World Health Organization, (accessed 6 October 2018).

\section{WHO 2017b}

World Health Organization. The evaluation process for vector control products. apps.who.int/iris/bitstream/ handle/10665/255644/WHO-HTM-GMP-2017.13-eng.pdf? sequence=1 2017 .

\section{Wilson 2015}

Wilson AL, Boelaert M, Kleinschmidt I, Pinder M, Scott TW, Tusting LS, et al. Evidence-based vector control? Improving the quality of vector control trials. Trends in Parasitology 2015;31(8):380-90.

\section{References to other published versions of this review} Pryce 2017

Pryce J, Choi L, Malone D. Insecticide space spraying for preventing malaria transmission. Cochrane Database of Systematic Reviews 2017, Issue 6. [DOI: 10.1002/14651858.CD012689]

* Indicates the major publication for the study

\section{Hobbs 1976}

Methods

Study design: controlled before-and-after (CBA) study

Unit of allocation: village (Cangrejera village chosen as intervention village due to house accessibility by road; the nearby Melara village was selected as the control village due to its similar housing, agricultural practices and vector density) Number of units: $1: 1$ 
Hobbs 1976 (Continued)

Outcome assessment/surveillance type: passive case detection through local collaboration centres, where suspected cases could report and a blood smear would be taken. This has previously been shown to be a sensitive surveillance method. Mosquito densities were measured using New Jersey light traps 1 night per week.

Adjustment for clustering: none

\begin{tabular}{ll}
\hline Participants & Number of participants: $408: 485$ \\
\hline Interventions & Active ingredient and dosage: pyrethrin, 0.002 to 0.0025 lbs per acre \\
& Formulation: $5 \%$ pyrethrin synergized with $15 \%$ piperonyl butoxide \\
& Droplet density: not described \\
& Droplet diameter: not described \\
& Thermal/Cold (ULV) fog: ULV \\
& Ground/Aerial: Ground, using truck-mounted sprayer \\
& Frequency of spraying: weekly, for 4 months (1st week May - last week August 1974, coinciding with the \\
peak malaria transmission season) & Time of spraying: 6 pm - 7 pm, to coincide with activity of female An albimanus \\
& Size of treated area: not described \\
& Buffer size between clusters: 3 km \\
Caged mosquito outcomes: 81.5 - $100.0 \%$ mortality (0.0 - $15.6 \%$ in control) \\
Control: no space spraying \\
Co-interventions (type, access, compliance): not described
\end{tabular}

Outcomes measured:
- number of cases of Plasmodium falciparum malaria
- An albimanus density
$\begin{aligned} & \text { Length of follow-up: } 15^{\text {th }} \text { June to } 15^{\text {th }} \text { September (both in } 1973 \text {, pre-spray, and } 1974 \text {, during the inter- } \\ & \text { vention) }\end{aligned}$

Location Profile Study location: villages in the coastal plain east of La Libertad, El Salvador.

Plasmodium species: falciparum and vivax

Vector Profile Primary vector species: An albimanus

Phenotypic resistance profile: moderately to highly resistant to dichlorodiphenyltrichloroethane (DDT), dieldrin, malathion, and propoxur

Method of mosquito collection: mosquito densities were measured using New Jersey light-traps 1 night a week, from sunset until sunrise. Densities were measures the night before a spray round

Notes CBA; not included in the meta-analysis

Funding source: unknown

Potential conflicts of interest: none known

\section{Krogstad 1975}

\section{Methods}

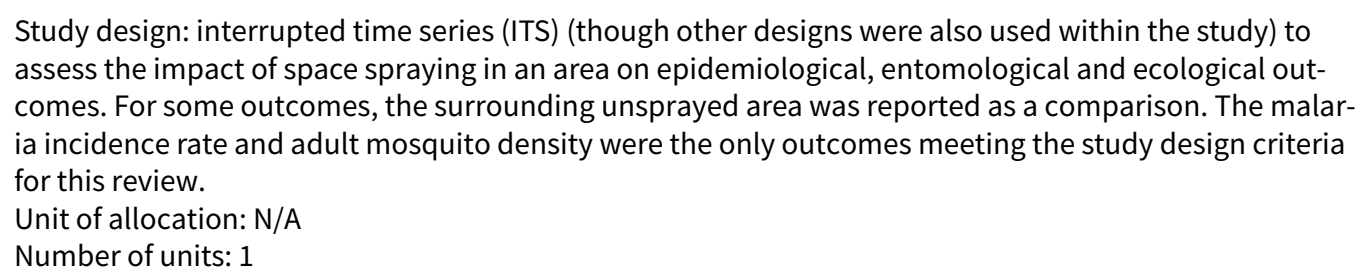
assess the impact of space spraying in an area on epidemiological, entomological and ecological outcomes. For some outcomes, the surrounding unsprayed area was reported as a comparison. The malaria incidence rate and adult mosquito density were the only outcomes meeting the study design criteria for this review.

Unit of allocation: N/A

Number of units: 1 
Outcome assessment/surveillance type: incidence of malaria assessed using a combination of active case detection (paid workers visiting each house in the area once every 2 weeks; blood smears were examined for all residents reporting malaria symptoms) and passive case detection (blood smears examined for those reporting to voluntary collaborators with malaria symptoms). Mosquito density and biting rates measured using updraft UV light-traps and human-baited biting collections

Adjustment for clustering: none

Participants

Number of participants: 15,106 living in sprayed area (31,710 including unsprayed area) Population characteristics: of the $31,710,39 \%<15$ years old

Interventions Active ingredient and dosage: malathion 95\%, 6 oz per acre for first cycle and 4.5 oz per acre for all subsequent cycles

Formulation: not described

Droplet density: 20 - 47 droplets per square inch

Droplet diameter: 40 - $50 \mu \mathrm{m}$ (open sites) and 25 - $40 \mu \mathrm{m}$ (protected sites)

Thermal/Cold (ULV) fog: ULV

Ground/Aerial: aerial (Beech D-18 aircraft equipped with 2 × 65-gallon fibreglass spray tanks. Flat fan $8002 \mathrm{E}$ spray nozzles were installed beneath the wings facing $45^{\circ} \mathrm{down}$ and forward). The aircraft was flown at a speed of $140 \mathrm{mph}$ and an altitude of 150 feet

Frequency of spraying: every 10 days, with an extra application 5 days after the initial spray. 6 applications were made over a 45-day period

Time of spraying: not reported

Size of treated area: 20,000 acres

Buffer size between clusters: N/A

Caged mosquito outcomes: caged mosquitoes in the sprayed area showed $100 \%$ mortality within 2 hours after spraying

Control: N/A

Co-interventions (type, access, compliance): IRS with DDT

Epidemiological outcomes measured:
- incidence of malaria
- slide positivity rate
Entomological:
- adult mosquito density (measured using both light-traps and human baits)
Ecological (note- not following suitable study design for inclusion in review):
- bird abundance
- AChE levels in bats, birds, lizards and fish
Length of follow-up: 5 months (October $1972-$ March 1973). Sprays were scheduled to begin when epi-
demic levels were reached (100 cases/month/10,000 population).

Location Profile

Study location: Miragoane Valley, southern peninsula, Haiti. The area has a natural barrier of mountain ranges which were expected to limit immigration of mosquitoes from adjacent unsprayed areas

Malaria endemicity: perennial and seasonal with persistent pattern of outbreaks, from October into January

Vector Profile

Primary vector species: Anopheles albimanus

Vector behaviour (nature, stability, adult habitat, peak biting times, exophilic/endophilic, exophagic/endophagic, anthropophilic/zoophilic): breed in marshes surrounding shallow lakes in the valley floor. Adults rest in dense sugar canes and banana groves

Phenotypic resistance profile: susceptible to malathion (in preliminary tests: $92 \%$ mortality at $0.8 \%$ malathion, $100 \%$ mortality at $1.6 \%$ malathion. $0 \%$ mortality in controls) 
Method of mosquito collection: 9 updraft UV light-traps at 3 collection sites, operating from 5.30pm to 5.30am Human-baited biting collections measured over 1 hour at 2 locations in each of the 3 collection sites ( 1 near breeding sites and 1 near houses)

\begin{tabular}{ll}
\hline Notes & Funding source: unknown \\
& Potential conflicts of interest: none known
\end{tabular}

\section{Risk of bias}

\begin{tabular}{lll}
\hline Bias & Authors' judgement & Support for judgement \\
\hline $\begin{array}{l}\text { Was the intervention inde- } \\
\text { pendent of other changes? }\end{array}$ & Unclear risk & $\begin{array}{l}\text { There is a lack of detail of concurrent control measures such as IRS, and en- } \\
\text { vironmental factors such as rainfall; the impact of these is therefore hard to } \\
\text { measure }\end{array}$ \\
& &
\end{tabular}

\begin{tabular}{|c|c|c|}
\hline $\begin{array}{l}\text { Was the shape of the inter- } \\
\text { vention effect pre-speci- } \\
\text { fied? }\end{array}$ & Low risk & The point of the analysis is the point of the intervention \\
\hline $\begin{array}{l}\text { Was the intervention un- } \\
\text { likely to affect data collec- } \\
\text { tion? }\end{array}$ & Low risk & $\begin{array}{l}\text { The sources and methods of data collection were the same before and after } \\
\text { the intervention }\end{array}$ \\
\hline $\begin{array}{l}\text { Was knowledge of the al- } \\
\text { located interventions ade- } \\
\text { quately prevented? }\end{array}$ & Unclear risk & $\begin{array}{l}\text { Unlikely that the outcomes were assessed blindly. Incidence measurements } \\
\text { depended on self-reporting of fever symptoms that may be influenced by par- } \\
\text { ticipant knowledge of the intervention, although parasitaemia was confirmed } \\
\text { by blood smear. Mosquito density measurements were objective and unlikely } \\
\text { to be influenced by this knowledge }\end{array}$ \\
\hline
\end{tabular}

\begin{tabular}{|c|c|c|}
\hline $\begin{array}{l}\text { Were incomplete out- } \\
\text { come data adequately ad- } \\
\text { dressed? }\end{array}$ & Low risk & No missing outcome data likely to bias the results \\
\hline $\begin{array}{l}\text { Was the study free from } \\
\text { selective outcome report- } \\
\text { ing? }\end{array}$ & Low risk & $\begin{array}{l}\text { The study design states that vector densities were also recorded in unsprayed } \\
\text { areas but these are not reported. This may show a reduction in densities for } \\
\text { reasons other than spraying. However, as time series data were used for this } \\
\text { outcome, we did not consider this selective reporting likely to cause a bias in } \\
\text { the results reported in this review }\end{array}$ \\
\hline
\end{tabular}

Was the study free from $\quad$ Low risk
other risks of bias?

Seleena 2004

Study design: CBA study with 4 treatment arms:
- space spraying with chemical adulticide
- space spraying with biological larvicides
- space spraying of both chemical adulticide and biological larvicides
- untreated control arm
Unit of allocation: village
Outcome assessment/surveillance type:
Incidence rate was monitored by passive (through the Ranau health office) and active case detection
(through monthly mass blood surveys covering $\sim 70 \%$ of the population)


Adjustment for clustering: none

Participants

Number of participants: 178 (intervention); 216 (control). A further 285 participants were included in the remaining arms of the study not relevant to this review

Population characteristics: not described
Active ingredient and dosage: alphacypermethrin, $2 \mathrm{~g} \mathrm{Al} / 10^{4} \times \mathrm{m}^{2}$

Formulation: alphacypermethrin (Fendona SC/Fendona 10SCR) was mixed with sieved stream water

Droplet density: not described

Droplet diameter: $111.0 \mu \mathrm{m}$ to $191.0 \mu \mathrm{m}$

Thermal/Cold fog (ULV): ULV

Ground/Aerial: ground, with hand-held sprayers

Frequency of spraying: monthly

Time of spraying: not described

Size of treated area: not described

Buffer size between clusters: at least 3.5 to $6.0 \mathrm{~km}$

Caged mosquito outcomes: not described

Control: no space spraying of adulticide or larvicide

Co-interventions (type, access, compliance): IRS and the use of insecticide-impregnated mosquito nets (lambdacyhalothrin and deltamethrin nets)

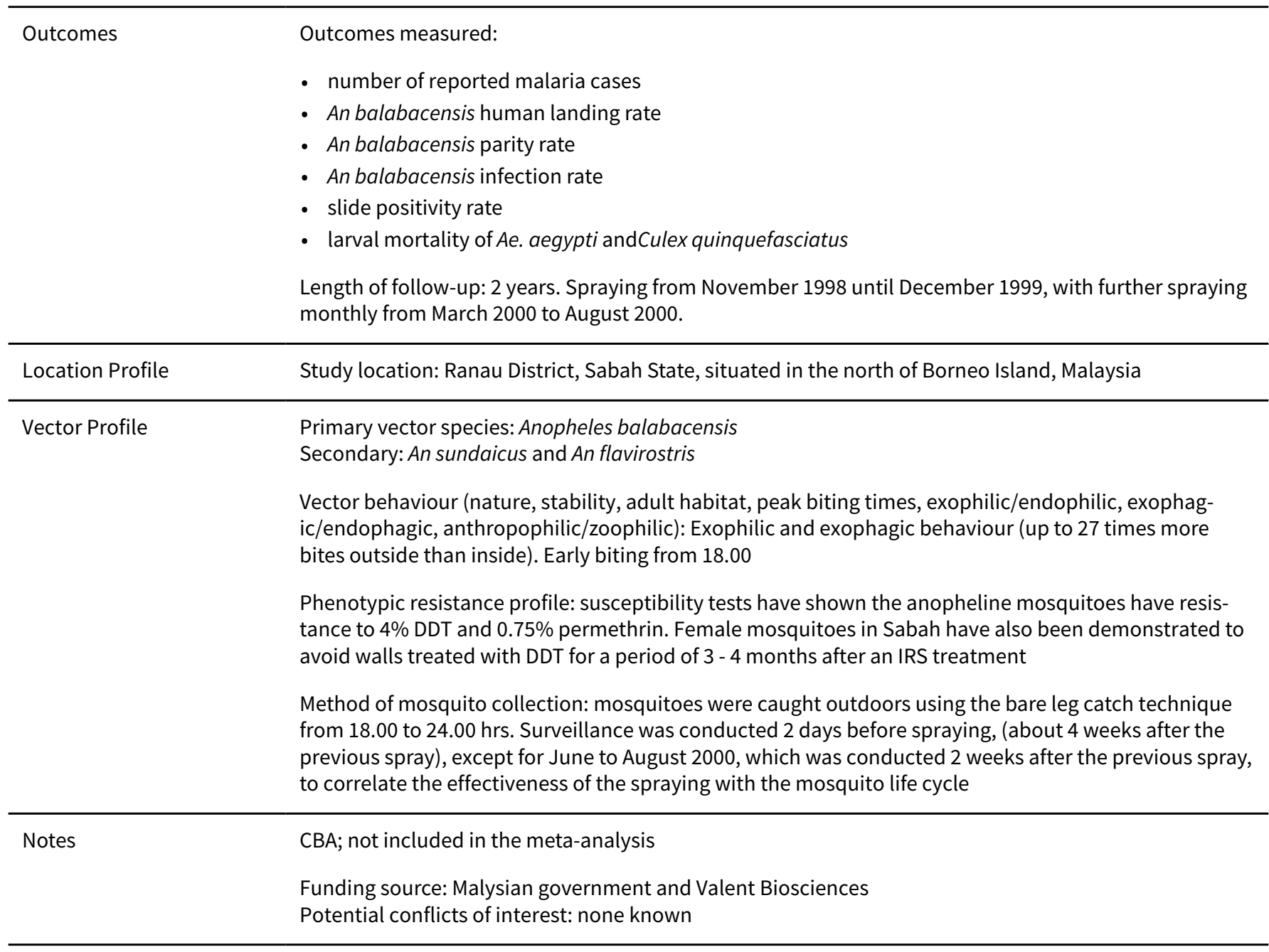


Study design: ITS (though other designs were also used within the study) to assess the impact on epidemiological and short-term entomological outcomes, following spraying with a variety of equipment and formulations. For some outcomes, nearby unsprayed areas are reported as a comparison. In Pudupettai, however, the control group was contaminated as it received space spraying 3 times, and because there was only 1 cluster in this arm, the control group is not a valid comparison. The malaria incidence rate is the only outcome that meets the study design criteria for this review.

Unit of allocation: N/A

Number of units: $\mathrm{N} / \mathrm{A}$

Outcome assessment/surveillance type: routine surveillance and treatment carried out by the State National Malaria Programme. Incidence rate was monitored through fever surveillance conducted at fortnightly intervals in 6 villages - Porasapattu and Pudur (Pudupettai PHC), Agarampallipattu, Edathanur, Kolamanjanur and Sathanur Dam (Vanapuram PHC), selected on the basis of a high incidence of malaria (API ranging from 25.4 - 105.9) Fever cases led to a blood smear examination. Mass blood surveys were carried out in 11 villages, including the index villages, in March - April and again in October November of each year of the study

Adjustment for clustering: none

Participants Number of participants: the population receiving the intervention is not reported. For the analysis, we have estimated population sizes using census data one's impact on entomological outcomes.

\section{Pudupettai:}

Active ingredient and dosage: malathion, 325 - $375 \mathrm{~mL}$ per hectare

Formulation: technical grade malathion

Droplet density: N/S

Droplet diameter: $27.1-28.6 \mu \mathrm{m}$

Thermal/cold (ULV) fog: ULV

Ground/aerial: Ground spraying, using 2 different hand-held sprayers

Frequency of spraying: fortnightly

Caged mosquito outcomes: $83.5 \%-96.2 \%$ indoor mortality. $55.1 \%-81.1 \%$ outdoor mortality $<50$ m

\section{Vanapuram (except Sanathur Dam):}

Active ingredient and dosage: malathion, $150 \mathrm{~mL}$ per hectare

Formulation: $5 \%$ technical grade malathion in diesel

Droplet density: N/S

Droplet diameter: $37.4 \mu \mathrm{m}$

Thermal/cold (ULV) fog: thermal

Ground/aerial: ground spraying, using Enfog hand-held sprayer

Frequency of spraying: fortnightly

Caged mosquito outcomes: $88.5 \%-92.4 \%$ indoor mortality. $31.3 \%$ outdoor mortality $<50 \mathrm{~m}$

\section{Melpallipattu (and Sanathur Dam):}

Active ingredient and dosage: malathion, 263 - $300 \mathrm{~mL}$ per hectare

Formulation: $5 \%$ technical grade malathion in diesel (and in some cases 10\%)

Droplet density: N/S

Droplet diameter: $22.7-65.7 \mu \mathrm{m}$

Thermal/cold (ULV) fog: thermal

Ground/aerial: ground spraying, using jeep-mounted Tifa and handcart-mounted Tiga machines

Frequency of spraying: fortnightly (except Sanathur Dam: weekly, due to village's specific problems)

Caged mosquito outcomes: $60.4 \%-100 \%$ indoor mortality. $74.1 \%-98.4 \%$ outdoor $<250 \mathrm{~m}$

Time of spraying: $2000 \mathrm{hr}-2200 \mathrm{hr}$, and $0500 \mathrm{hr}-0700 \mathrm{hr}$.

Size of treated area: N/S

Buffer size between clusters: N/A 
Tewari 1990 (Continued)

Control: N/A

Co-interventions (type, access, compliance): residual spraying with malathion conducted 3 times each year (April - May, July - August and September - October)

Outcomes measured:
- incidence of malaria
- prevalence (no measurements recorded prior to intervention, or in control area)
- slide positivity rate
- An culicifacies density - (indoor/outdoor resting rates and biting rate) - (Measurements before and
after a single spraying cycle)
- parity
Length of follow-up: 4 years (January 1981 - December 1984). Spraying operations were conducted in
- 2 villages in Pudupettai (February 1981 - December 1982)
- 24 villages in Vanapuram (February 1982 - December 1984)
- 3 villages in Melpallipattu (August 1982 - December 1984)

Study location: 3 sites along the Thenpennai riverine tract in Tamil Nadu state, India. These are
Pudupettai (then South Arcot district; now Viluppuram district), Vanapuram, and Melpallipattu (then
North Arcot district, now Tiruvannamalai district). Due to the unique epidemiological challenges of
malaria transmission in Sathanur Dam village in Vanapuram, the results from Sathanur Dam are report-
ed separately to Vanapuram, providing 4 distinct study sites

Plasmodium species: $73.1 \%$ vivax, $21.5 \%$ falciparum, $5.4 \%$ mixed

Pector Profile
$\begin{aligned} & \text { Pector behaviour (nature, stability, adult habitat, peak biting times, exophilic/endophilic, exophag- } \\ & \text { ic/endophagic, anthropophilic/zoophilic): Shows some exophilic behaviour } \\ & \text { Phenotypic resistance profile: resistant to DDT. Susceptible to malathion } \\ & \text { Method of mosquito collection: indoor/outdoor timed resting catches (days 1, 2, } 3 \text { and } 11 \text { after each } \\ & \text { spray), and indoor/outdoor all-night human baited collections (day } 3 \text { after spraying) }\end{aligned}$

spray), and indoor/outdoor all-night human baited collections (day 3 after spraying)

$\begin{array}{ll}\text { Notes } & \text { Funding source: unknown } \\ & \text { Potential conflicts of interest: none known }\end{array}$

\section{Risk of bias}

Bias Authors' judgement Support for judgement

Was the intervention inde- Low risk pendent of other changes?
The concurrent IRS rounds were conducted in the same way as previous years and so would not explain a change in trend. The possibility that the decline was caused by lower than average rainfall in 1982 is unlikely, as villages sprayed in 1981 saw a decline in the same year, and the downward trend continued despite normal to heavy rainfall in 1983 and 1984

The point of analysis is the point of the intervention

Was the shape of the inter- Low risk vention effect pre-speci-

fied?

\begin{tabular}{|c|c|c|}
\hline $\begin{array}{l}\text { Was the intervention un- } \\
\text { likely to affect data collec- } \\
\text { tion? }\end{array}$ & Low risk & $\begin{array}{l}\text { The methods of data collection were the same before and after the interven- } \\
\text { tion }\end{array}$ \\
\hline
\end{tabular}


Tewari 1990 (Continued)

Was knowledge of the al- Unclear risk Unlikely that the outcomes were assessed blindly. Incidence measurements located interventions ade- depended on self-reporting of fever symptoms that may be influenced by parquately prevented? ticipant knowledge of the intervention, although parasitaemia was confirmed by blood smear

\begin{tabular}{lll}
$\begin{array}{l}\text { Were incomplete out- } \\
\text { come data adequately ad- } \\
\text { dressed? }\end{array}$ & Low risk & No missing outcome data likely to bias the results \\
\hline $\begin{array}{l}\text { Was the study free from } \\
\text { selective outcome report- } \\
\text { ing? }\end{array}$ & High risk & $\begin{array}{l}\text { The report states that 24 villages in Vanapuram were sprayed but a time s } \\
\text { of the number of cases and slide positivity rate is only presented for } 4 \text { of t } \\
\text { villages }\end{array}$ \\
\hline $\begin{array}{l}\text { Was the study free from } \\
\text { other risks of bias? }\end{array}$ & Unclear risk & $\begin{array}{l}\text { A variety of spray equipment and formulations are used and is unclear at } \\
\text { which times and locations each has been used }\end{array}$ \\
\hline
\end{tabular}

Abbreviations: Al: active ingredient; CBA: controlled before-and-after; DDT: dichlorodiphenyltrichloroethane; ITS: interrupted time series; N/A: not applicable; N/S: not stated.

Characteristics of excluded studies [ordered by study ID]

Study Reason for exclusion

Adam 1964

Did not meet inclusion criteria for study design. The report documents a control campaign using multiple vector control activities undertaken simultaneously including indoor spraying, larviciding, drainage and destruction of potential breeding sites, as well as outdoor spraying. The campaign did not compare an intervention area with an untreated control group or provide a time series with data points prior to the intervention.

Afridi 1962

Did not meet inclusion criteria for study design. The report is not a trial, rather a history of the medical services of the Indian Armed Forces in the Second World War, including malaria control alongside other medical services such as nutrition and disease prevention. The two main methods described for controlling malaria were residual spraying with dichlorodiphenyltrichloroethane (DDT) and drug prophylaxis, adding to previous methods of larviciding and larval habitat modification.

Bown 1981

Did not meet inclusion criteria for intervention type. The study compared a village receiving ULV application with technical-grade malathion with a village receiving no intervention. However, applications of malathion were both indoor and outdoor, and therefore the intervention is not suitable for inclusion in the review. The study also reported no epidemiological outcomes, only entomological indices (adult landing rates, resting densities, and ovitrap recordings).

\section{Cáceres G 2013}

Did not meet inclusion criteria for intervention type. The report documents the response to an epidemic of malaria in Venezuela in 2002. The country reported the highest recorded incidence of malaria in its history with 51,264 cases, surpassing the previous high of 5893 in 1990. The primary intervention used was preventive treatment by mass drug administration using 'cloroquinine' and 'primaquinine'. This intervention was supplemented with space spraying. There was no control group for the intervention.

De Andrade 1986

Did not meet inclusion criteria for study design. The paper documents the response to an outbreak of malaria in São Paulo State of Brazil in 1984. It is not a trial and has no control group. Space spraying is conducted using DDT. The report documents the treatment of the cases.

Escudie 1963

Did not meet inclusion criteria for intervention type. The intervention tested in the study was a residual insecticide dispenser which was placed within study houses, and dispensed dichlorvos insecticide. One study village was compared against one control village where houses did not receiv- 


\section{Study Reason for exclusion}

er dichlorvos dispensers. Blood samples were drawn from all children up to 10 years old for smear and thick blood film examinations, once before and seven times after dichlorvos treatment.

Harper 1947

Did not meet inclusion criteria for study design. The report is not a trial, rather a history of the control methods employed to prevent malaria and other tropical diseases in the Second World War, South Pacific Campaign (1942 - 1945). A number of interventions are described that were employed simultaneously, including careful choice of camp sites, habitat modification, larviciding from the ground (paris-green dust, oil and later DDT solution or dust) or from aircraft (DDT solution), space spraying with pyrethrum aerosols and residual DDT preparations, impregnating bed nets, screening, semi-permanent and permanent control work and suppressive medication.

Mason 1977

Did not meet inclusion criteria for study design. The report documents the incidence of malaria and density of the primary vector species in a coastal region of El Salvador, over a period in which several interventions were implemented in the study area. These included aerial application of the larvicide Abate, two cycles of mass drug distribution with amodiaquine, and one application cycle of the residual insecticide propoxur, applied to the exterior walls of each house in the area. The report is not a clinical trial and no control group was examined

Did not meet inclusion criteria for study design. The report documents the slide positivity for malaria and density of the vector species in Farukkhabad district, India, over a period in which several interventions were implemented in the study area. These included indoor residual spraying (IRS) with DDT, space spraying with $5 \%$ or $6 \%$ malathion, larviciding with Baytex, and mass drug administration with chloroquine, primaquine, and metakelfin. The report is not a clinical trial and no control group was examined.

Did not meet inclusion criteria for study design. The report documents the success of a control programme in Basrah Liwa, Iraq, as it replaced DDT for use in IRS with malathion in some areas, where high resistance to DDT was detected alongside susceptibility to malathion. During the study, high amounts of flooding contributed to higher than usual transmission of the disease. To combat this, a range of measures were introduced, including space spraying with diazinon, intensified larviciding measures, aerial spraying with DDVP, and mass drug administration. The report is not a clinical trial and no control group was examined.

Sharma 1986

Did not meet inclusion criteria for study design. The study evaluated the impact of space spraying on lab-reared caged mosquitoes only, which were placed at different sites in a region sprayed with malathion. The report is not a clinical trial and no control villages were studied, although control caged mosquitoes were monitored, in cages placed outside of spraying areas.

Strickman 2001

Did not meet inclusion criteria for study design. The report documents the incidence of malaria and density of the primary vector species in a military camp in South Korea, over a period in which several interventions were implemented in the study area. These included personal protection such as topical repellents, permethrin-treated clothing and mosquito nets, window screens, indoor spraying with permethrin, and ULV space spraying with piperanyl butoxide. The report is not a clinical trial and no control group was examined. vehicle-mounted Leco machines (where villages were accessible by road) and hand-held Fontan sprayers (where villages were not accessible by road) on mosquito density was evaluated in the Solomon Islands.

No control group was monitored. Two outcomes were monitored: the man-biting rate, and mosquito sensitivity to spraying (using caged mosquitoes caught in the previous nights' man-biting collections). Man-biting rates were recorded before, during, and several days after spraying. Without three time points prior to the intervention implementation, the study did not meet the criteria for an ITS study.

Viswanathan 1950

Did not meet inclusion criteria for study design. The report is not a trial, but summarizes the actions of the Bombay State malaria organization set up in 1942 and its impact on malaria transmission and vector populations. The paper describes the range of interventions that have been used 


\begin{tabular}{ll}
\hline Study & Reason for exclusion \\
\hline Warren 1985 & $\begin{array}{l}\text { including drug administration, mosquito larvicides, habitat modification and space spraying, be- } \\
\text { fore the introduction of IRS with DDT. }\end{array}$ \\
\hline $\begin{array}{l}\text { Did not meet inclusion criteria for intervention type. The report is an investigation into the impact } \\
\text { on sprayers' (i.e. those who have carried out IRS in a trial in Haiti) urinary metabolites and blood } \\
\text { cholinesterase levels. }\end{array}$ \\
\hline $\begin{array}{l}\text { Full text was not available. We consider the study unlikely to be included, as the abstract appears } \\
\text { to describe IRS (though published before the term was commonly used) rather than space spray- } \\
\text { ing. }\end{array}$ \\
\hline
\end{tabular}

Abbreviations: DDT: dichlorodiphenyltrichloroethane; IRS: indoor residual spraying.

\section{DATA AND ANALYSES}

Comparison 1. Space spraying versus no space spraying

\begin{tabular}{|c|c|c|c|c|}
\hline Outcome or subgroup title & No. of studies & $\begin{array}{l}\text { No. of partici- } \\
\text { pants }\end{array}$ & $\begin{array}{l}\text { Statistical } \\
\text { method }\end{array}$ & Effect size \\
\hline $\begin{array}{l}1 \text { Incidence of malaria (step rate ratio: indicating } \\
\text { the impact of space spraying at the first pre-inter- } \\
\text { vention time point) }\end{array}$ & 1 & & $\begin{array}{l}\text { Rate Ratio (Ran- } \\
\text { dom, } 95 \% \mathrm{Cl} \text { ) }\end{array}$ & $1.00[0.51,1.92]$ \\
\hline $\begin{array}{l}2 \text { Incidence of malaria (slope rate ratio: indicating } \\
\text { the proportion of cases reduced per post-inter- } \\
\text { vention time point) }\end{array}$ & 1 & & $\begin{array}{l}\text { Rate Ratio (Ran- } \\
\text { dom, 95\% Cl) }\end{array}$ & $0.85[0.79,0.91]$ \\
\hline
\end{tabular}

\section{Analysis 1.1. Comparison 1 Space spraying versus no space spraying, Outcome 1 Incidence of malaria (step rate ratio: indicating the impact of space spraying at the first pre-intervention time point).}

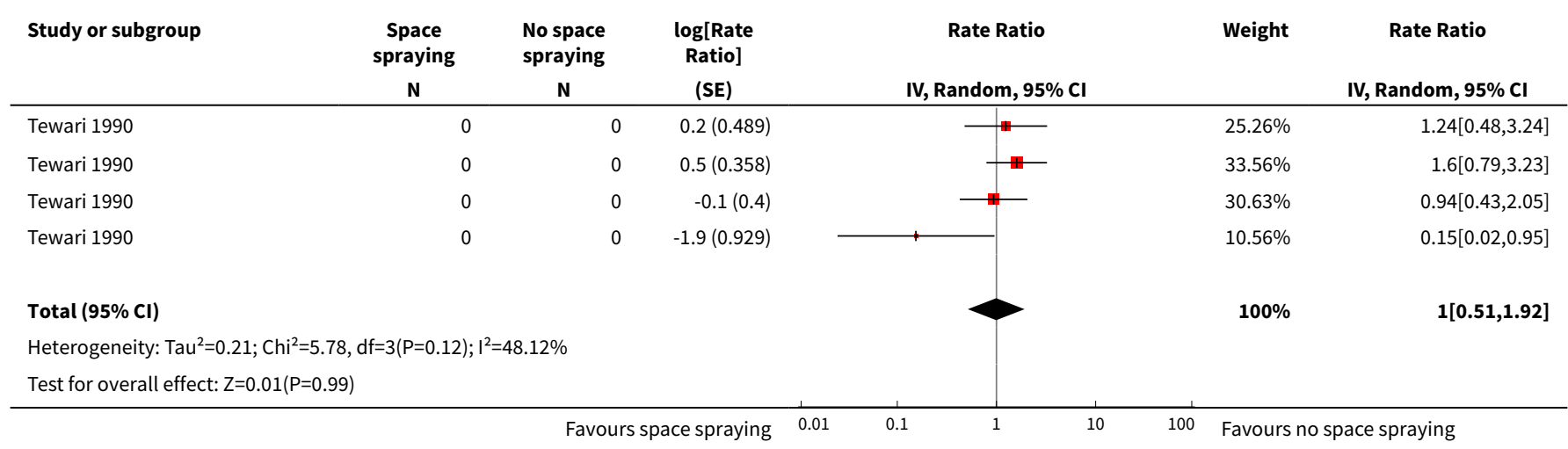


Analysis 1.2. Comparison 1 Space spraying versus no space spraying, Outcome 2 Incidence of malaria (slope rate ratio: indicating the proportion of cases reduced per post-intervention time point).

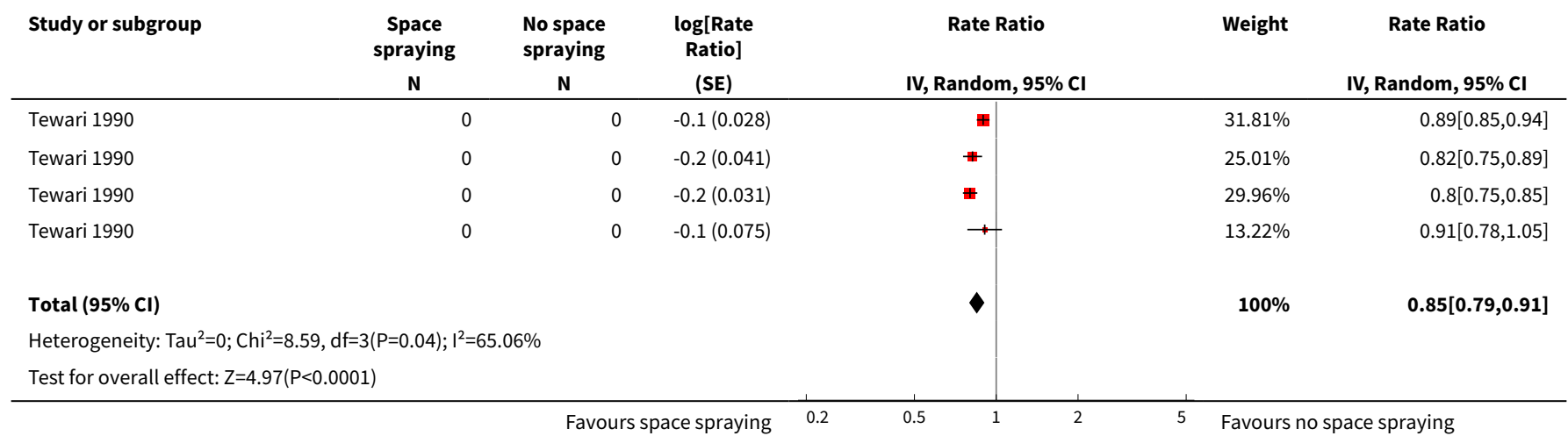

ADDITIONAL TABLES

Table 1. WHO-recommended insecticides for space spraying against mosquitoes

\begin{tabular}{lll}
\hline Compound and formulation & \multicolumn{1}{c}{ Concentration (g Al/ha) } & Thermal fog \\
\cline { 2 - 3 } & Cold fog & 0.5 to 1.0 \\
\hline Deltamethrin ULV & 0.5 to 1.0 & - \\
\hline Deltamethrin EW & 1.0 & 2.0 \\
\hline Lambda-cyhalothrin EC & 1.0 to 2.0 & 112 to 600 \\
\hline Malathion EW and ULV & 112 to 600 & 3.5 to 4.0 \\
\hline d-d, trans-Cyphenothrin EC & 3.5 to 4.0 & 2.0 \\
\hline
\end{tabular}

Abbreviations: EC: emulsifiable concentrate; EW: emulsion, oil in water; ULV: ultra-low volume liquid; Al: active ingredient

Table 2. Operational characteristics of studies

\begin{tabular}{|c|c|c|c|c|c|}
\hline Study & $\begin{array}{l}\text { Active ingredi- } \\
\text { ent/formula- } \\
\text { tion/dose }\end{array}$ & $\begin{array}{l}\text { Delivery } \\
\text { method }\end{array}$ & $\begin{array}{l}\text { Frequency and timing of ap- } \\
\text { plication }\end{array}$ & $\begin{array}{l}\text { Who implemented } \\
\text { the intervention }\end{array}$ & $\begin{array}{l}\text { Vector } \\
\text { species }\end{array}$ \\
\hline $\begin{array}{l}\text { Haiti } \\
\text { (Krogstad } \\
1975)\end{array}$ & $\begin{array}{l}\text { Malathion } 95 \% \\
\text { - ULV fog } \\
\text { - } 6 \mathrm{oz} / \text { acre (1st cy- } \\
\text { cle) } \\
\text { - } 4.5 \mathrm{oz} / \mathrm{acre}\end{array}$ & $\begin{array}{l}\text { Aerial (Beech } \\
\text { D-18 aircraft) }\end{array}$ & $\begin{array}{l}\text { Every } 10 \text { days } \\
\text { Extra application } 5 \text { days after } \\
\text { the initial spray } \\
\text { Time of spraying: not stated }\end{array}$ & $\begin{array}{l}\text { The Service National } \\
\text { d'Eradication de } \\
\text { la Malaria (SNEM), } \\
\text { supported by USAID }\end{array}$ & An albimanus \\
\hline $\begin{array}{l}\text { India (Tewari } \\
\text { 1990) }\end{array}$ & $\begin{array}{l}\text { Malathion } \\
\text { - ULV and thermal } \\
\text { - dose varied de- } \\
\text { pending on }\end{array}$ & $\begin{array}{l}\text { Ground (hand- } \\
\text { held Fontan } \\
\text { and Enfog } \\
\text { sprayers, jeep- } \\
\text { mounted Tifa }\end{array}$ & $\begin{array}{l}\text { In Pudupettai, spraying } \\
\text { was conducted weekly for } 6 \\
\text { rounds, and subsequently ap- } \\
\text { plied in response to new cases } \\
\text { or increases in vector density. }\end{array}$ & $\begin{array}{l}\text { State National Malar- } \\
\text { ia Elimination Pro- } \\
\text { gramme (NMEP), } \\
\text { with guidance from } \\
\text { the Pondicherry Vec- }\end{array}$ & An culicifacies \\
\hline
\end{tabular}


Table 2. Operational characteristics of studies (Continued)

sprayer (150 to 375 $\mathrm{mL} / \mathrm{ha})$

See Characteristics of included studies for further details machines and handcart-mounted

Tiga machines
In Vanapuram and Melpallipattu spraying was conducted fortnightly, in all but one village (Sathanur Dam) where spraying was conducted weekly

Time of spraying: 8pm - 10pm and 5am - 7am tor Control Research

Centre
Central America

Research Station

(CARS)
An albimanus mounted Leco sprayer)
Time of spraying: $6 \mathrm{pm}-7 \mathrm{pm}$

\author{
$5 \%$ pyrethrin with
} toxide

El Salvador

- ULV fog

- 0.002 to 0.0025 lbs/acre

\begin{tabular}{|c|c|c|c|c|c|}
\hline $\begin{array}{l}\text { Malaysia } \\
\text { (Seleena } \\
\text { 2004) }\end{array}$ & $\begin{array}{l}\text { Alphacypermethrin } \\
\text { - } 2 \mathrm{~g} \mathrm{Al} / 10^{4} \times \mathrm{m}^{2}\end{array}$ & $\begin{array}{l}\text { Ground, with } \\
\text { hand-held } \\
\text { sprayers }\end{array}$ & $\begin{array}{l}\text { Monthly } \\
\text { Time of spraying: not stated }\end{array}$ & $\begin{array}{l}\text { Spray team of vil- } \\
\text { lagers, headed by a } \\
\text { local public health } \\
\text { inspector }\end{array}$ & $\begin{array}{l}\left(1^{0}\right) \text { Anopheles } \\
\text { balabacensis } \\
\left(2^{\circ}\right) \text { An } \\
\text { sundaicus, An } \\
\text { flavirostris }\end{array}$ \\
\hline
\end{tabular}

Abbreviations: Al: active ingredient; ULV: ultra-low volume.

\section{APPENDICES}

\section{Appendix 1. Detailed search strategies \\ CENTRAL}

Issue 4 of 12, April 2018

ID Search Hits

\#1 "malaria":ti,ab,kw (Word variations have been searched)

\#2 MeSH descriptor: [Malaria] explode all trees

\#3 MeSH descriptor: [Insect Vectors] explode all trees

\#4 mosquito* or anophel*

\#5 MeSH descriptor: [Mosquito Control] explode all trees

\#6 MeSH descriptor: [Anopheles] explode all trees

$\# 7$ \#1 or \#2 or \#3 or \#4 or \#5 or \#6 4652

\#8 aerosol* or droplet* or "cold fog*" or "thermal fog* " or "space spray*" or fogging or misters

\#9 "Mist Blower" or "fumigant canister*" or "aerial spray*" or "spray* equipment" or "ultralow volume" or "ultralow-volume" or ULV \#10 MeSH descriptor: [Aerosols] explode all trees

\#11 MeSH descriptor: [Fumigation] explode all trees

$\# 12 \# 8$ or \#9 or \#10 or \#11

$\# 13 \# 7$ and \#12

Insecticide space spraying for preventing malaria transmission (Review) 
MEDLINE

\begin{tabular}{|c|c|}
\hline Search set & Search terms \\
\hline 1 & Malaria* Title/Abstract, [Mesh] \\
\hline 2 & "Insect Vectors"[Mesh] OR vector* ti, ab OR mosquito* or anophel* Title/Abstract \\
\hline 3 & 1 or 2 \\
\hline 4 & "Mosquito Control"[Mesh] \\
\hline 5 & "Anopheles"[Mesh] \\
\hline 6 & 3 or 4 or 5 \\
\hline 7 & $\begin{array}{l}\left.\left.\text { ((((aerosol*) OR droplet }{ }^{\star}\right) \text { OR "cold fog*") OR "thermal fog }{ }^{\star} "\right) \text { OR space spray* OR fogging OR mis- } \\
\text { ters Title/Abstract }\end{array}$ \\
\hline 8 & $\begin{array}{l}\text { "Mist Blower" OR "fumigant canister" OR "aerial spray" OR "spray* equipment" OR "ultralow vol- } \\
\text { ume" OR "ultralow-volume" OR ULV Title/Abstract }\end{array}$ \\
\hline 9 & "Aerosols"[Mesh] \\
\hline 10 & "Fumigation"[Mesh] \\
\hline 11 & 7 OR 8 OR 9 OR 10 \\
\hline 12 & 6 AND 11 \\
\hline
\end{tabular}

\section{Embase}

1 malaria/ or malaria.mp.

2 insect vector/

3 (mosquito* or anophel $\left.^{\star}\right) \cdot \mathrm{mp}$.

4 mosquito control.mp. or mosquito control/

5 exp Anopheles/

61 or 2 or 3 or 4 or 5

7 (aerosol* or droplet* or "cold fog*" or "thermal fog ${ }^{\star " ~ o r ~ " s p a c e ~ s p r a y * " ~ o r ~ f o g g i n g ~ o r ~ m i s t e r s) . m p . ~}$

8 pesticide spraying/

9 ("Mist Blower" or "fumigant canister" or "aerial spray*" or "spray* equipment" or "ultralow volume" or "ultra-low volume" or ULV).mp 10 aerosol/

11 fumigation.mp. or fumigation/

127 or 8 or 9 or 10 or 11

136 and 12 
CABI: CAB Abstracts ${ }^{\circledR}$

\begin{tabular}{ll}
\hline Set & \\
\hline$\# 3$ & \#4 AND \#2 \\
& Indexes=CAB Abstracts Timespan=All years \\
\hline$\# 2$ & TOPIC: (malaria or anopheles) \\
& Indexes=CAB Abstracts Timespan=All years \\
\hline$\# 1$ & TOPIC: (aerosol* or droplet* or "cold fog*" or "thermal fog* " or "space spray*" or fogging or mis- \\
& ters) OR TOPIC: ("Mist Blower" or "fumigant canister " or "aerial spray*" or "spray* equipment" or \\
& "ultralow volume" or ULV) \\
& Indexes=CAB Abstracts Timespan=All years \\
\hline
\end{tabular}

\section{LILACS}

(tw:(malaria OR anopheles)) AND (tw:(aerosol* OR droplet* OR "cold fog*" OR "thermal fog* " OR "space spray*" OR fogging OR misters OR "Mist Blower" OR "fumigant canister*" OR "aerial spray*" OR "spray^ equipment" OR "ultralow volume" OR ulv)) AND (instance:"regional") AND ( db:("LILACS"))

\section{WHO ICTRP}

Mosquito AND "space spraying"

Mosquito AND spraying

Mosquito AND insecticides

\section{ClinicalTrials.gov}

Mosquito AND "space spraying"

Mosquito AND spraying

Mosquito AND insecticides

\section{CONTRIBUTIONS OF AUTHORS}

JP, LC, and DM developed the protocol.

JP and LC screened search outputs, selected trials for inclusion, extracted the data, and assessed risk of bias with support from DM as required.

MR conducted the modelling analysis and provided statistical support throughout.

JP, LC, and MR conducted the GRADE analysis.

JP prepared the draft manuscript, with contributions from all authors. All review authors have seen and approved the final manuscript.

\section{DECLARATIONS OF INTEREST}

JP has no known conflicts of interest.

LC has no known conflicts of interest.

MR has no known conflicts of interest.

During the completion of the review, DM was employed by the Innovative Vector Control Consortium (IVCC). The title of the review is related to the use of insecticide applications for malaria vector control. The IVCC as an organization has a programme of working with industry on the development of novel insecticides and other vector control tools. The IVCC has no current programmes specifically related to the development of space spray insecticides, but one project relates to their use in a malaria transmission setting. Since completing the review, DM has joined Sumitomo Chemicals, a manufacturer of vector control products. 


\section{SOURCES OF SUPPORT}

\section{Internal sources}

- Liverpool School of Tropical Medicine, UK.

\section{External sources}

- Department for International Development, UK.

Project number 300342-104

- World Health Organization (WHO), Switzerland.

WHO Global Malaria Programme Agreement for Performance of Work (APW) Grant 2017 (number 709319)

\section{DIFFERENCES BETWEEN PROTOCOLAND REVIEW}

The main difference between the review and the protocol is the clarification of the methods used for analysis of the ITS studies. Firstly, we did not anticipate that the studies would not tabulate outcome data, and we therefore needed to use a plot digitizer to extract this. Secondly, we were required to estimate numbers of the treated population by using census data for the treated villages, as these numbers were not reported for each study site. It also became apparent that the impact of space spraying on a time series of outcome data could be interpreted as both a step and a slope change. We therefore treated the step change and the slope change as different outcomes of the intervention, and we adopted the methodology from Bernal 2017 to estimate the step rate ratio and slope rate ratio. Finally, we calculated both the step change in malaria incidence and the effect of the slope change after 12 months of space spraying, and presented both findings in Summary of findings for the main comparison.

\section{INDEX TERMS}

\section{Medical Subject Headings (MeSH)}

${ }^{\star}$ Insecticides; Aerosols; Incidence; India [epidemiology]; Interrupted Time Series Analysis; Malaria [epidemiology] [ ${ }^{\star}$ prevention \& control] [*transmission]; Mosquito Control [methods]

\section{MeSH check words}

Animals; Humans 